\title{
Relevance of Cortical and Hippocampal Interneuron Functional Diversity to General Anesthetic Mechanisms: A Narrative Review
}

\author{
Iris A. Speige $I^{1 *}$ and Hugh C. Hemmings Jr. ${ }^{1,2}$ \\ ${ }^{1}$ Department of Anesthesiology, Weill Cornell Medicine, New York, NY, United States, ${ }^{2}$ Department of Pharmacology, Weill \\ Cornell Medicine, New York, NY, United States
}

\section{OPEN ACCESS}

Edited by:

Leonardo Pignataro, The City University of New York, United States

Reviewed by: Armando Salinas, Louisiana State University Health Shreveport, United States Roman Vlkolinsky, The Scripps Research Institute, United States

${ }^{*}$ Correspondence: Iris A. Speigel ias2006@med.cornell.edu

Received: 10 November 2021 Accepted: 30 December 2021 Published: 26 January 2022

Citation: Speigel IA and Hemmings HC Jr. (2022) Relevance of Cortical and Hippocampal Interneuron Functional

Diversity to General Anesthetic

Mechanisms: A Narrative Review. Front. Synaptic Neurosci. 13:812905. doi: 10.3389/fnsyn.2021.812905
General anesthetics disrupt brain processes involved in consciousness by altering synaptic patterns of excitation and inhibition. In the cerebral cortex and hippocampus, GABAergic inhibition is largely mediated by inhibitory interneurons, a heterogeneous group of specialized neuronal subtypes that form characteristic microcircuits with excitatory neurons. Distinct interneuron subtypes regulate specific excitatory neuron networks during normal behavior, but how these interneuron subtypes are affected by general anesthetics is unclear. This narrative review summarizes current principles of the synaptic architecture of cortical and interneuron subtypes, their contributions to different forms of inhibition, and their roles in distinct neuronal microcircuits. The molecular and cellular targets in these circuits that are sensitive to anesthetics are reviewed in the context of how anesthetics impact interneuron function in a subtype-specific manner. The implications of this functional interneuron diversity for mechanisms of anesthesia are discussed, as are their implications for anesthetic-induced changes in neural plasticity and overall brain function.

Keywords: anesthesia, cerebral cortex, hippocampus, interneurons, isoflurane, ketamine, plasticity

\section{INTRODUCTION}

The mechanistic understanding of general anesthesia has seen substantial recent progress, but there is a conceptual gap between the molecular pharmacology of anesthetic targets and the network level changes in the anesthetized central nervous system (CNS). General anesthetics alter the balance and dynamics of neural excitation and inhibition at the levels of single receptors, synapses, and circuits. Neural inhibition is largely mediated by GABAergic interneurons in the brain, with biochemically and functionally distinct interneuron subtypes responsible for different forms of synaptic and circuit inhibition. Specialized interneurons are adapted for specific neural circuit roles (Kepecs and Fishell, 2014). Although largely overlooked in studies of anesthetic mechanisms, interneuron diversity has implications for understanding how general anesthetics alter CNS function at the micro-, meso- and macro-circuit levels.

Interneurons release the major inhibitory neurotransmitter gamma-aminobutyric acid (GABA) to stabilize the membrane potential away from the action potential threshold, either by hyperpolarization or shunting inhibition, effectively controlling neurotransmission in target cells. The interneuron function has classically described "local" effects within the same anatomical region as the cell body and dendrites. However, recent findings 
demonstrate small populations of cortical and hippocampal GABAergic neurons with long-range projections (Jinno, 2009; Melzer and Monyer, 2020). Interneuron cellular and synaptic physiology vary due to differential gene and protein expression, including the expression of several established anesthetic targets, raising the possibility of interneuron subtype-specific and microcircuit-specific roles in determining overall network sensitivities to anesthetic agents and adjuvants. Interneurons have distinct roles in controlling excitatory neuron activity and shaping oscillatory dynamics, and therefore must be considered in explaining anesthetic effects on brain rhythms recorded intraoperatively under anesthesia. Moreover, experimental data suggest that anesthetics differentially modulate interneuron function, as outlined below. As interneuron plasticity has been associated with both positive and negative cognitive outcomes in various animal models (Lewis et al., 2012; Palop and Mucke, 2016; Luscher et al., 2020), these effects have implications for both deleterious and beneficial long-term effects.

Here we review cortical and hippocampal interneuron diversity in the context of the neurophysiological mechanisms and consequences of general anesthesia. We describe the architecture for interneuron specialization, including their heterogeneous expression of known molecular targets for various anesthetics, and discuss evidence of interneuron subtype-specific anesthetic sensitivities determined by differential expression of these anesthetic targets. We also discuss evidence that changes in interneuron function contribute to the persistent effects of anesthesia, and summarize preclinical evidence for altered interneuron function in both positive and negative changes in brain function following anesthetic exposure. Finally, we propose approaches to elucidate the roles of interneurons in anesthetic mechanisms and discuss the advanced methods that could address current questions.

\section{INTERNEURON SUBTYPES: PHYSIOLOGICAL PROPERTIES AND SYNAPTIC TARGETS}

We chose to focus this review on cortical and hippocampal interneurons in part because we have the most advanced understanding of the fundamental inhibitory systems governing excitatory neuron output and network function in these brain regions. However, anesthesia is a composite state with several distinct behavioral endpoints (unconsciousness, amnesia, immobility, and analgesia) attributed to different brain regions. For example, loss of consciousness alone involves not only the cortex but also the thalamus, subcortical regions, and the brainstem. It is difficult to compare cortical and hippocampal interneuron systems with those in other brain regions critical for anesthesia in part because the basic neuroanatomy differs. However, interneurons do share common features and embryological origins, such that the overlapping pharmacological effects may be generalizable.

In the cerebral cortex and hippocampus GABAergic interneurons represent only $\sim 10-20 \%$ of total neurons, however, they exert a disproportionately large impact on functional network outputs. By definition, inhibitory interneurons synthesize and release GABA by one of two glutamic acid decarboxylase isoforms (GAD65 and GAD67). However, many GABAergic interneurons also corelease various neuromodulators and neuropeptides that define them both immunocytochemically and functionally. Interneuron subpopulations include multiple subtypes (Figure 1) with characteristic phenotypes for modulation of excitability, action potential (AP) firing behavior, synaptic connectivity, and network-level functions. This broad functionality is driven largely by differential expression of protein effectors related to synaptic transmission (Paul et al., 2017).

Below we outline the defining characteristics of prominent cortical and hippocampal interneuron subtypes following conventional classification (Petilla Interneuron Nomenclature Group et al., 2008). Cortical and hippocampal interneuron subtypes can be discussed together because many of their characteristics and circuit roles are conserved; other review articles provide more detailed region-specific classifications (Pelkey et al., 2017; Lim et al., 2018). In general, distinct interneuron subtypes have characteristic neurophysiological properties and form stereotypical synaptic connections or microcircuits with excitatory neurons, which usually provide microcircuit output by innervating distinct subcellular targets (e.g., soma, dendrite, axon, bouton).

Parvalbumin-expressing $\left(\mathbf{P V}^{+}\right)$interneurons are the most extensively characterized interneuron subtype in terms of their cellular properties and circuit function. $\mathrm{PV}^{+}$interneurons preferentially innervate excitatory neurons for fast phasic signaling and large-scale synchronized network activity ( $\mathrm{Hu}$ and Jonas, 2014). Basket cells target the cell body and proximal dendrites, and chandelier cells target the axon initial segment. Functionally $\mathrm{PV}^{+}$cells are typified by a "fast firing" $(>50 \mathrm{~Hz})$ response to depolarizing current injection without accommodation (diminished spike height during a train). In contrast, excitatory pyramidal neurons and most other interneurons have lower maximal firing rates and show spike accommodation with AP height rapidly declining during a sustained depolarization. $\mathrm{PV}^{+}$cells have the highest maximal firing rate of hippocampal neurons $(>300 \mathrm{~Hz})$, critical for participation in high-frequency network activity. The AP waveform of $\mathrm{PV}^{+}$interneurons is also unique compared to excitatory neurons and other interneurons, characterized by a narrow profile (short half-width) and a large, brief afterhyperpolarization due to high axonal expression of kinetically fast $\mathrm{K}^{+}$channels ( $\mathrm{Hu}$ et al., 2018). $\mathrm{PV}^{+}$interneurons receive synaptic drive from local excitatory neurons and thalamocortical neurons and thus are sensitive to thalamocortical oscillations (Hafner et al., 2019). $\mathrm{PV}^{+}$interneuron activity is further synchronized by extensive dendritic gap junctionmediated electrical coupling ( $\mathrm{Hu}$ and Jonas, 2014).

$\mathrm{PV}^{+}$synaptic terminals are specialized by a short delay and brief duration. In contrast to pyramidal neurons, which express multiple presynaptic $\mathrm{Ca}^{2+}$ channel subtypes with varying gating kinetics, $\mathrm{PV}^{+}$terminals express only $\mathrm{P} / \mathrm{Q}$-type $\mathrm{Ca}^{2+}$ channels with fast gating kinetics. Synaptic $\mathrm{Ca}^{2+}$ channels and synaptic vesicles are arranged closer together for "tight" coupling with 


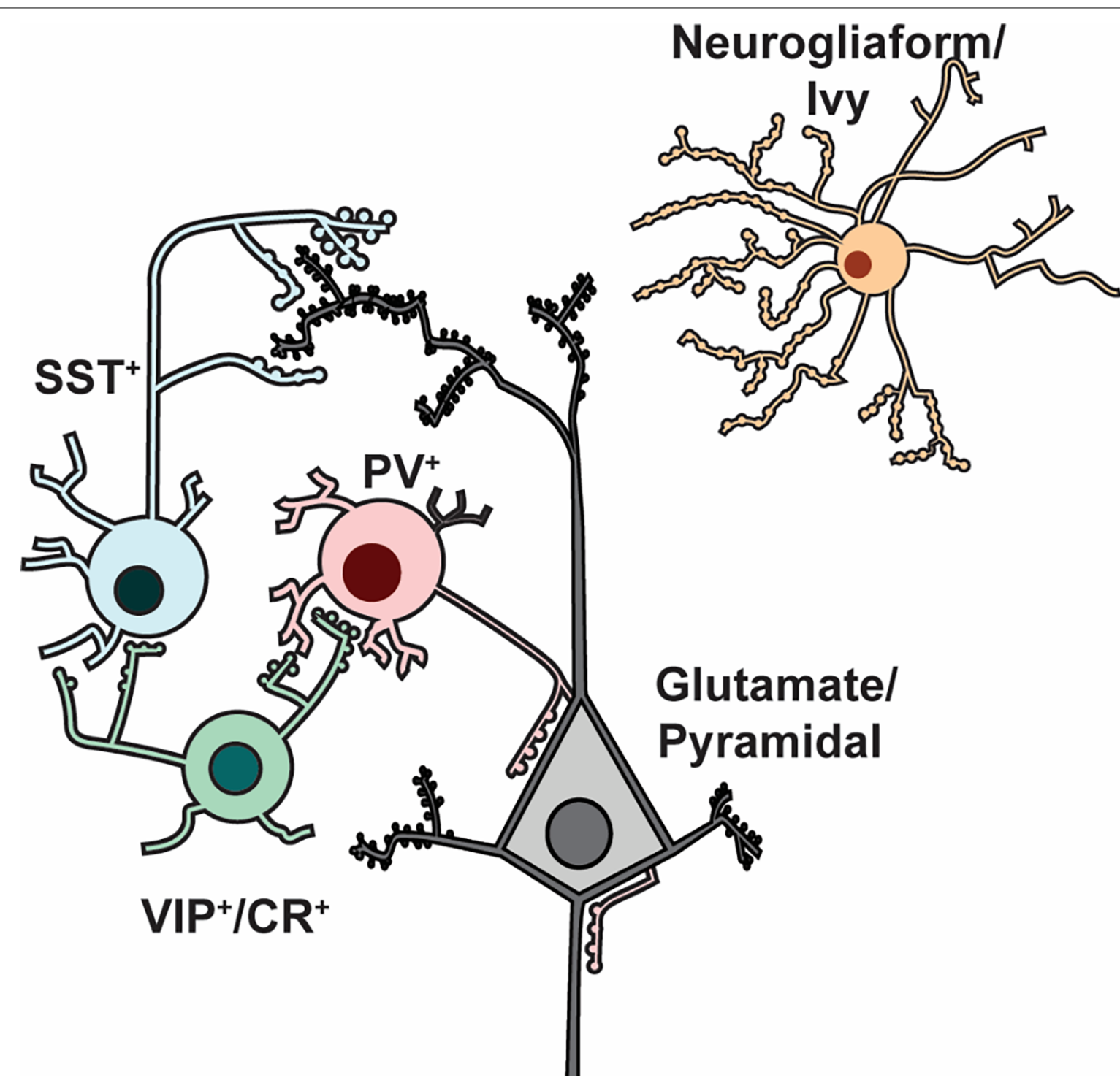

FIGURE 1 | Major interneuron subtypes. Cartoon illustration of prominent interneuron subtypes of the cortex and hippocampus, showing their stereotypical arrangements with each other and with glutamatergic/pyramidal neurons. $\mathrm{PV}^{+}$(parvalbumin-expressing) interneurons preferentially make axo-somatic and axo-axonic synapses onto glutamatergic pyramidal neurons, whereas SST${ }^{+}$interneurons target pyramidal neuron dendrites. $\mathrm{VIP}^{+} / \mathrm{CR}^{+}$interneurons target $\mathrm{PV}^{+}$and $\mathrm{SST}^{+}$interneurons to disinhibit pyramidal neurons. Neurogliaform/ivy cell axons generally form a dense network of terminals that do not form classic synapses but instead release GABA volumetrically. This simplified diagram does not illustrate laminar distributions and morphology, which vary by region.

the $\mathrm{Ca}^{2+}$-sensitive synaptic vesicle exocytotic proteins (Hu et al., 2014). On a network level, $\mathrm{PV}^{+}$interneurons control oscillatory rhythm generation and pacing and have been proposed to underlie gamma-band activity $(20-80 \mathrm{~Hz})$ in the cortical electroencephalogram (EEG; Cardin et al., 2009; Sohal et al., 2009). The relationship between $\mathrm{PV}^{+}$interneurons and gamma frequency is being studied in relation to attention and memory, with implications for cognitive dysfunction in schizophrenia and Alzheimer's disease (Lewis et al., 2012; Klein et al., 2016).

Somatostatin-expressing $\left(\mathrm{SST}^{+}\right)$interneurons are the primary source of axo-dendritic inhibitory synapses onto excitatory neurons in the hippocampus (Yavorska and Wehr, 2016).
Most cortical $\mathrm{SST}^{+}$interneurons are further defined as Martinotti cells based on the morphological profile of the oriens lacunosum-moleculare (OLM) and a single prominent axon that projects superficially. Hippocampal SST ${ }^{+}$interneurons, named OLM and hilar perforant path-associated (HIPP) neurons, are considered the functional homologs of cortical Martinotti cells and share a similar morphology ${ }^{4}$.

Martinotti $\mathrm{SST}^{+}$neurons are non-fast firing, show spike adaptation, and have a maximum firing rate far lower than $\mathrm{PV}^{+}$ interneurons. The AP is wider due to differential voltage-gated $\mathrm{Na}^{+}$and $\mathrm{K}^{+}$channel expression and kinetics. $\mathrm{SST}^{+}$interneurons have a higher intrinsic excitability than $\mathrm{PV}^{+}$interneurons, with a lower AP threshold and high basal activity in the theta 


\section{Anesthetic targets in interneurons}

\begin{tabular}{|c|c|}
\hline Parvalbumin (PV+) & Somatostatin (SST $\left.{ }^{+}\right)$ \\
\hline $\begin{array}{l}\delta \mathrm{GABA}_{\mathrm{A}} \mathrm{Rs} \\
\mathrm{K}_{\mathrm{v}} 3.2 \\
\text { TASK-3 } \\
\text { HCN (terminals) } \\
\text { P/Q-type Ca } \mathrm{s} \\
\text { L-type, T-type } \mathrm{Ca}_{\mathrm{v}} \mathrm{s} \\
\mathrm{Na} \mathrm{v}_{\mathrm{v}} 1.1>1.2,1.6 \\
\text { NMDARs }\end{array}$ & $\begin{array}{l}\alpha 5 \text { GABA }{ }_{A} \text { s }(\mathrm{VIP} \rightarrow \mathrm{SST}) \\
\mathrm{K}_{\mathrm{v}} 3.1 \\
\text { TASK-3 } \\
\text { HCN (dendrites) } \\
\text { P/Q-type Ca } \mathrm{s} \\
\text { L-type, T-type } \mathrm{Ca}_{\mathrm{v}} \mathrm{s} \\
\mathrm{Na}_{\mathrm{v}} 1.1,1.2,1.6 \\
\text { NMDARs }\end{array}$ \\
\hline $\begin{array}{c}\text { Vasoactive Intestinal } \\
\text { Peptide }\left(\text { VIP }^{+}\right)\end{array}$ & \multirow{2}{*}{$\begin{array}{l}\text { Neurogliaform and Ivy } \\
\text { ¿ GABA Rs } \\
\text { nNOS }\end{array}$} \\
\hline $\begin{array}{l}\text { 5-HT3ARs } \\
\mathrm{Na}_{v} 1.1,1.2,1.6 \\
\text { NMDARs }\end{array}$ & \\
\hline
\end{tabular}

FIGURE 2 | Anesthetic targets in interneurons. Highlighted anesthetic targets that are differentially expressed amongst the prominent interneuron subtypes from Figure 1. Anesthetic effects on specific targets and cells are complex and anesthetic agent-specific, so they are not shown in the figure. Please see the text for a discussion of the direction, potency, and implications of specific anesthetic effects. Abbreviations: GABAARs, $\gamma$-aminobutyric acid type A receptors; $K_{v} 3.1 / K_{v} 3.2$, voltage-gated potassium channels; TASK-3, TWIK-related acid-sensitive potassium channel subtype 3; HCN, Hyperpolarization-activated cyclic nucleotide-gated channels; $\mathrm{Na}_{v}$, voltage-gated sodium channels, with the $\mathrm{Na}_{v} 1.1$ subtype being more abundant in $\mathrm{PV}+$ interneurons; NMDAR $\mathrm{N}_{\mathrm{S}}$-methyl-D-aspartate receptors; 5-HT3 $\mathrm{R}$, 5-hydroxytryptamine type 3A receptors; nNOS, neuronal nitric oxide synthase.

\section{Anesthetic-induced interneuron plasticity}

\begin{tabular}{|c|c|}
\hline$\frac{\text { Parvalbumin }\left(\mathrm{PV}^{+}\right)}{\downarrow \text { Nlgn-1/Erb4 expression (isoflurane) }}$ & $\int_{\downarrow \text { learning activity (prenatal propofol) }}^{\text {Somatostatin }\left(\mathrm{SST}^{+}\right)}$ \\
\hline $\begin{array}{l}\uparrow \text { GluN2B expression (prenatal ketamine) } \\
\uparrow \text { firing activity (brief isoflurane via } \\
\text { BDNF/TrkB) } \\
\text { لlearning activity (prenatal propofol) }\end{array}$ & $\left(\begin{array}{c}\begin{array}{c}\text { Vasoactive Intestinal } \\
\left.\text { Peptide (VIP }{ }^{+}\right)\end{array} \\
\uparrow \text { learning activity (prenatal propofol) }\end{array}\right.$ \\
\hline
\end{tabular}

FIGURE 3 | Anesthetic-induced interneuron plasticity. Review of evidence for persistent changes in interneuron function following anesthetic exposure. Abbreviations: Nlgn1/Erb4, signaling between neuroligin-1 and its receptor ErbB4; GluN2b, N-methyl D-aspartate receptor subunit 2B; BDNF, brain-derived neurotrophic factor; TrkB, tropomyosin receptor kinase B.

bandwidth $(3-10 \mathrm{~Hz}) . \mathrm{SST}^{+}$interneurons are primarily excited by pyramidal neurons and inhibited by $\mathrm{VIP}^{+}$interneurons. $\mathrm{VIP}^{+} / \mathrm{SST}^{+}$axo-dendritic synapses express $\mathrm{GABA}_{\mathrm{A}}$ receptors containing the high-affinity $\alpha 5$ subunit consistent with strong inhibition (Magnin et al., 2019).

$\mathrm{SST}^{+}$synapses target the distal dendrites of excitatory neurons and can selectively inhibit specific inputs, unlike
$\mathrm{PV}^{+}$interneurons that target excitatory cell bodies and soma post-integration to prevent firing (Urban-Ciecko and Barth, 2016). SST ${ }^{+}$interneuron terminals release SST, a neuroactive peptide that exerts a variety of presynaptic and postsynaptic effects, mostly inhibitory (Liguz-Lecznar et al., 2016). SST is not co-released with GABA during normal synaptic vesicle exocytosis, rather it is released from 
dendritic and axonal dense-core vesicles following repetitive high-frequency stimulation. Because SST has antiepileptic activity, an endogenous homeostatic or protective role has been suggested (Tallent and Qiu, 2008). At the network, SST ${ }^{+}$ interneurons have a critical role in generating slow wave EEG activity associated with sleep (Funk et al., 2017).

\section{INTERNEURON- SELECTIVE/DISINHIBITORY INTERNEURONS}

About $20 \%$ of hippocampal and $15 \%$ of cortical interneurons express VIP and/or calretinin (CR) and selectively target other interneurons. This circuit role is thought to disinhibit local excitatory cells by creating holes in the "blanket of inhibition", and/or modulate spatiotemporal patterns of inhibition and tune the excitatory cell input/output firing relationship (Karnani et al., 2014). $\mathrm{VIP}^{+} / \mathrm{CR}^{+}$interneurons are part of the $5 \mathrm{HT}^{\mathrm{A}}$ receptorexpressing interneuron group discussed below (Lee et al., 2010).

$\mathrm{VIP}^{+}$interneuron-selective interneurons show a variety of unique spiking behaviors during sustained depolarization including "irregular" behavior with single APs firing randomly; "bursting" behavior with three-five high-frequency APs discharged initially, followed by single APs at random intervals"; and "stuttering" behavior with clusters of spikes separated by silent periods of varying duration (Posluszny, 2019). VIP ${ }^{+}$ interneurons preferentially target $\mathrm{SST}^{+}$interneurons and a fraction of $\mathrm{PV}^{+}$interneurons (Turi et al., 2019).

Whether VIP is also released as a modulator from these interneurons is unknown. This is an interesting possibility since VIP applied directly to hippocampal CA1 and CA3 in vitro increases pyramidal cell excitability (Haas and Gahwiler, 1992). Related suprachiasmatic $\mathrm{VIP}^{+} /$GABAergic neurons release VIP for postsynaptic modulation of inhibitory postsynaptic currents and postsynaptic neuron firing rate(Itri and Colwell, 2003). About $15 \%$ of cortical and $30 \%$ of prefrontal $\mathrm{VIP}^{+}$interneurons also co-release acetylcholine and participate in the regulation of attention (Obermayer et al., 2019).

In vivo, hippocampal $\mathrm{VIP}^{+}$interneuron-selective interneurons are recruited at the peak of wake-state theta oscillations and are silent during ripples (Luo et al., 2020). In the prefrontal cortex, they are active during discrimination tasks. Guet-McCreight and colleagues reviewed recent studies into hippocampal and cortical $\mathrm{VIP}^{+}$and $\mathrm{CR}^{+}$interneuron-containing circuits, with special comparisons for distinct cortical regions with comparable actions (Guet-McCreight et al., 2020). Across these subregions, VIP/CR ${ }^{+}$disinhibition commonly serves to control the integration of input to excitatory neurons and to control synaptic plasticity.

Neurogliaform cells of the cortex and hippocampus and ivy cells of the hippocampus mediate slow inhibition and share a unique morphology. An axonal "plexus" forms a high density of terminals without clear postsynaptic appositions (Armstrong et al., 2012). Instead of releasing GABA via classical synaptic exocytosis, these terminals release GABA in a volumetric "cloud" onto local processes that generates long-lasting inhibitory postsynaptic currents. Conceptually this volumetric release mode lies between phasic and tonic transmission (Olah et al., 2009; Overstreet-Wadiche and McBain, 2015). They also express a unique late-spiking AP phenotype that allows "slow integration" of input prior to firing. Spikes are non-accommodating and speed up during depolarization. Repetitive activity can elicit a late-spiking variation called barrage firing, where hundreds of APs occur at $\sim 20-130 \mathrm{~Hz}$ for up to several seconds to minutes. This has been proposed to operate as an "excitability brake" (Sheffield et al., 2013; Overstreet-Wadiche and McBain, 2015).

Ivy cells and many neurogliaform cells also express neuronal nitric oxide synthase (nNOS) which creates the gaseous transmitter nitric oxide (NO) that has both presynaptic and postsynaptic actions (Hardingham et al., 2013). nNOS activity and NO signaling have been investigated as targets for volatile anesthetics, but roles remain unresolved. Volatile anesthetics alter NO production in cultured cerebellar neurons (Rengasamy et al., 1997; Loeb et al., 1998; Sjakste et al., 1999), however, NO loss of function animal models have shown both increased or decreased anesthetic sensitivity (Engelhardt et al., 2006; Nagasaka et al., 2017). Future investigations into these signaling pathways are needed to delineate the exact preclinical mechanisms and their contributions to the behavioral and clinical effects of anesthetics.

\section{INTERNEURONS IN OSCILLATIONS: IMPLICATIONS FOR THE MACROSCOPIC RHYTHMS OF ANESTHESIA}

The ensemble coordinated activity of distinct interneurons is thought to be critical for controlling global network activity and cognitive function (Buzsaki and Chrobak, 1995). This is supported by observations that interneuron subtypes preferentially fire at specific phases of oscillatory rhythms (Klausberger and Somogyi, 2008), and that interneuron subtypespecific perturbations alter oscillatory rhythms and behavior. How distinct interneurons shape the oscillation patterns that characterize induction and emergence from general anesthesia remains unclear mechanistically.

Modeling studies of patient forebrain EEG data collected intraoperatively usually represent synaptic connections as either excitatory or inhibitory. As a notable exception, Hashemi and colleagues found that tonic inhibition potentiated via extrasynaptic $\mathrm{GABA}_{\mathrm{A}}$ receptors in interneurons could model power surges in $\delta$ and $\alpha$ frequency ranges characteristic of propofol anesthesia (Hashemi et al., 2014). Tonic inhibition correlates with the expression of $\mathrm{GABA}_{\mathrm{A}} \alpha 5$-containing receptors in $\mathrm{SST}^{+}$interneurons and $\mathrm{GABA}_{\mathrm{A}} \delta$-containing receptors in $\mathrm{PV}^{+}$and neurogliaform/ivy interneurons which are very anesthetic sensitive (described below). In the basal forebrain associated with overlapping sleep and anesthesia circuits, selective activation of $\mathrm{SST}^{+}$but not of $\mathrm{PV}^{+}$interneurons results in increased sensitivity to isoflurane anesthesia and propofol anesthesia concomitant with potentiation of several EEG hallmarks of deep anesthesia including increased $\delta$ frequency power (Cai et al., 2021). How anesthetic potentiation 
of tonic inhibition in these cell types translates to cellular and circuit changes is not straightforward, as increased tonic inhibition has a cell-type-specific effect on neurophysiological parameters including gain control (Bryson et al., 2020).

Cell-type-based modeling can provide key insights into understanding network oscillatory behavior (Skinner, 2012; Keeley et al., 2017). Thus modeling studies of anesthetized human EEG data could be facilitated by incorporating elements that account for interneuron neurophysiological and pharmacological diversity.

\section{INTERNEURON MOLECULAR TARGETS FOR ANESTHESIA}

There are a number of identified anesthetic targets that are differentially expressed between interneuron subtypes. We highlight some examples with potential consequences for interneuron cellular and synaptic function (Figure 2). This is not meant to be an exhaustive review of known protein targets of volatile anesthetics, which have been reviewed recently (Hemmings et al., 2019). Rather, we focus on targets for which there are potential cell-type-specific effects such as evidence of differential expression between interneuron subtypes.

$\mathbf{K}^{+}$channels control intrinsic excitability and firing patterns by hyperpolarizing the membrane potential at rest and repolarizing the membrane potential following APs. Several superfamily members are sensitive to anesthetics (Li et al., 2018; Riegelhaupt et al., 2018). For interneurons, $\mathrm{K}^{+}$channel subtype and splice form expression are highly diverse, and several are associated with subtype-specific electrical characteristics (Casale et al., 2015; Pelkey et al., 2017). Voltage-gated $\mathrm{K}^{+}$channels $\left(\mathrm{K}_{\mathrm{v}}\right)$ shape the AP waveform. $\mathrm{K}_{\mathrm{v}} 3$ channels are activated by depolarized membrane potential during the AP and mediate rapid repolarization, enabling hippocampal $\mathrm{PV}^{+}$and $\mathrm{SST}^{+}$OLM interneurons to fire at a higher frequency than pyramidal neurons (Rudy and McBain, 2001). Fast-firing $\mathrm{PV}^{+}$interneurons utilize $\mathrm{K}_{\mathrm{v}} 3.2$ whereas non-fast firing $\mathrm{SST}^{+}$-OLM neurons utilize $\mathrm{K}_{\mathrm{v}} 3.1$ which has slightly slower deactivation kinetics (Pelkey et al., 2017). Although the sensitivity of $K_{v} 3.1$ to anesthetics has not been reported, other isoforms show interesting differences in pharmacology. Heterologously expressed $K_{v} 3.2$ is inhibited by volatile anesthetics yet activated by propofol, whereas $K_{v} 3.4$ is unaffected by either (Bhattacharji et al., 2010; Barber et al., 2011).

Two pore domain $\mathrm{K}^{+}(\mathbf{K} 2 \mathrm{P})$ channels, including the Twik-related acid-sensitive $\mathrm{K}^{+}$channel (TASK) subtype, mediate background leak conductance. Many forms of K2P are implicated in anesthesia and natural sleep cycles (Steinberg et al., 2015). Interneurons have relatively more TASK-3 and less TASK-1 compared to pyramidal neurons which express both. Heterologously expressed TASK-3 channels show greater potentiation by halothane than TASK-1 (Sirois et al., 2000). TASK-3 and TASK-1 knockout mice are both less sensitive to volatile anesthetics, have aberrant sleep/wake transition patterns, and their cortical EEG lacks theta oscillation (4-9 Hz; Pang et al., 2009). Because $\mathrm{PV}^{+}$and $\mathrm{SST}^{+}$interneurons are critical to theta oscillations and show strong immunoreactivity for TASK-3, this target may be a critical substrate for anesthetic effects on theta rhythms (Taverna et al., 2005).

Hyperpolarization-activated cation channels (HCN) participate in subthreshold excitability and rhythmicity; HCN inhibition by general anesthetics contributes to loss of consciousness and amnesia (Ying et al., 2006; Zhou et al., 2015). HCN channels are ubiquitously expressed among excitatory and inhibitory neurons, but different subcellular localization may impact anesthetic effects. Hippocampal excitatory neurons and probably $\mathrm{SST}^{+}$-OLM neurons express HCN channels mostly in the soma and dendrites (Zhou et al., 2015). In contrast, $\mathrm{PV}^{+}$ interneurons express $\mathrm{HCN}$ channels exclusively in axons and terminals which contribute to their high maximal AP frequency, so their fast-firing output may be anesthetic sensitive (Roth and $\mathrm{Hu}, 2020)$.

Voltage-gated $\mathrm{Na}^{+}$channels $\left(\mathrm{Na}_{\mathbf{v}}\right)$ are inhibited by volatile anesthetics (with depressed peak current and enhanced inactivation) resulting in AP depression and reduced presynaptic excitability. The CNS $\mathrm{Na}_{\mathrm{v}}$ channels have distinct anesthetic sensitivities and cellular expression patterns. $\mathrm{Na}_{\mathrm{v}} 1.1$ is enriched in interneurons (especially $\mathrm{PV}^{+}$) and is the least sensitive to volatile anesthetics, whereas $\mathrm{Na}_{\mathrm{v}} 1.2$ is more abundant in $\mathrm{SST}^{+}$interneurons and is more sensitive to volatile anesthetics (Zhou et al., 2019). In addition to the voltage-gated channels associated with AP upstroke, $\mathrm{Na}^{+}$leak channels (Ou et al., 2020; Yang et al., 2020) and persistently active channels (Zhao et al., 2019) are anesthetic-sensitive and contribute to anesthetic actions.

Commensurate with a critical role in $\mathrm{PV}^{+}$interneuron AP kinetics, $\mathrm{Na}_{\mathrm{v}} 1.1$ in $\mathrm{PV}^{+}$interneurons is necessary for normal oscillations at the network level, particularly gamma band activity, and for cognitive function. $\mathrm{Na}_{\mathrm{v}} 1.1$ expression is decreased in an Alzheimer's disease model, and their $\mathrm{PV}^{+}$ interneurons show abnormal cellular and synaptic physiology. Genetic rescue of $\mathrm{Na}_{\mathrm{v}} 1.1$ ameliorated $\mathrm{PV}^{+}$dysfunction, epileptiform discharges, and restored deficits in gamma band activity and cognitive function in this Alzheimer's disease model (Verret et al., 2012).

The ionotropic serotonin receptor $\left(\mathbf{5}-\mathbf{H T} \mathbf{3}_{\mathbf{A}} \mathbf{R}\right)$ is expressed in a large heterogeneous group of interneurons ( $~ 30 \%$ in the cortex, including $\mathrm{VIP}^{+} / \mathrm{CR}^{+}$disinhibitory interneurons) that can be depolarized by $5-\mathrm{HT} 3{ }_{\mathrm{A}} \mathrm{R}$ agonists (Lee et al., 2010). Anesthetic effects on 5 -HT3 ${ }_{\mathrm{A}}$ Rs have not been extensively investigated as fundamental for hypnosis, likely because blockade does not alter anesthetic potency in rats (Rampil et al., 2001), and the consequence of $5-\mathrm{HT} 3_{\mathrm{A}} \mathrm{R}$ modulation on interneuron activity is unknown. Heterologously expressed $5-\mathrm{HT} 3_{\mathrm{A}} \mathrm{R}$ is allosterically potentiated by volatile anesthetics (Solt et al., 2005; Stevens et al., 2005).

Developmentally, 5HT/5HT3aR signaling is critical for several prenatal and postnatal mechanisms of interneuron circuit formation including cell migration (Vitalis et al., 2007; Murthy et al., 2014).

Voltage-gated $\mathrm{Ca}^{2+}$ channel $\left(\mathrm{Ca}_{\mathbf{v}}\right)$ subtypes differ in biophysical parameters, cellular expression profiles, and roles for synaptic plasticity (Vinet and Sik, 2006; Yamamoto and Kobayashi, 2018). Presynaptic $\mathrm{Ca}_{\mathrm{v}} 2.1$ and $\mathrm{Ca}_{\mathrm{v}} 2.2$ (producing 
$\mathrm{P} / \mathrm{Q}$-type or $\mathrm{N}$-type currents, respectively) mediated $\mathrm{Ca}^{2+}$ entry controls synaptic vesicle exocytosis and neurotransmitter release. Excitatory synapses express a mixture of $\mathrm{P} / \mathrm{Q}$ and N-type channels to mediate synchronous glutamate release (Dolphin and Lee, 2020), however, some interneurons show preferential expression of distinct forms coupled to GABA release. Hippocampal $\mathrm{PV}^{+}$interneuron axosomatic terminals utilize fast P/Q-type channels for synchronous transmission. In contrast, axosomatic terminals from another type of interneuron expressing cholecystokinin $\left(\mathrm{CCK}^{+}\right)$utilize slower N-type channels and mediate asynchronous transmission (Hefft and Jonas, 2005; Zaitsev et al., 2007).

The question of how anesthetics affect P/Q- vs. N-type channel function is pertinent to understanding how distinct forms of inhibition are affected by anesthetics. Multiple studies demonstrate $\mathrm{Ca}_{\mathrm{v}}$ inhibition by anesthetics, but relative potencies vary with the heterologous expression system, brain region, and cell-type (reviewed by Orestes and Todorovic (2010)).

Voltage-gated $\mathrm{Ca}^{2+}$ channels also influence $\mathrm{Ca}^{2+}$-gated second messenger signaling cascades for activity-dependent plasticity. $\mathrm{Ca}_{\mathbf{v}} \mathbf{1 . 2}$ 1.3 (L-type) channel expression is highest in $\mathrm{PV}^{+}$and $\mathrm{SST}^{+}$interneurons. In $\mathrm{PV}^{+}$interneurons, and L-type $\mathrm{Ca}^{2+}$ channels participate in a novel cell-specific pathway for CREB phosphorylation and activity-dependent transcriptional regulation (Cohen et al., 2016). $\mathrm{PV}^{+}$interneuron development also involves an L-type $\mathrm{Ca}^{2+}$ channel-mediated transcriptional pathway (Jiang and Swann, 2005). Volatile anesthetics inhibit L-type channel conductance and G proteincoupled receptor signaling (Kamatchi et al., 2001; Fanchaouy et al., 2013). Thus L-type channel-dependent plasticity may be a target for changes in $\mathrm{PV}^{+}$interneuron function following anesthetic exposure (see below). $\mathrm{Ca}_{\mathbf{v}} 3$ (T-type) channels have also been associated with distinct forms of plasticity between hippocampal $\mathrm{PV}^{+}$and $\mathrm{SST}^{+}$synapses onto pyramidal neurons (Udakis et al., 2020).

$\mathrm{GABA}_{\mathbf{A}}$ receptors are well known as the major anesthetic target for postsynaptic facilitation of phasic and tonic inhibitory GABAergic signaling. Interneuron subtype-specific synapses differ in $\mathrm{GABA}_{\mathrm{A}}$ receptor subunit expression (Sperk et al., 1997; Contreras et al., 2019), which determines receptor function and pharmacology (Pirker et al., 2000; Bonin and Orser, 2008).

Interneurons differentially express the high GABA affinity $\alpha 4$, $\alpha 5$, and $\delta$ subunits often associated with extrasynaptic receptors, which detect micromolar GABA from synaptic spill-over and/or volumetric release to mediate persistent or tonic inhibition (Ferando and Mody, 2014). Anesthetic modulation of tonic conductance dampens excitability by reducing firing frequency and hyperpolarizing the resting membrane potential. $\mathrm{PV}^{+}$ interneurons and neurogliaform cells are enriched in $\delta$ subunits and show a prominent tonic GABA current sensitive to $\delta$ specific ligands like neurosteroids (Ferando and Mody, 2015). This input is critical for normal network function, as $\mathrm{PV}^{+}$interneuronselective $\delta$ subunit deletion impairs CA3 gamma oscillation frequency (Mann and Mody, 2010). Cortical neurogliaform neuron expression of $\delta$ tonic conductance may act as a feedback mechanism for volumetric GABA release (Olah et al., 2009).
In contrast, hippocampal $\mathrm{SST}^{+}$interneuron tonic inhibition is weak and insensitive to $\delta$ selective ligands (Vardya et al., 2008). Instead, $\mathrm{SST}^{+}$neurons receive inhibition from VIP-expressing interneurons via dendritic synapses onto postsynaptic a5 subunit-containing receptors, which are high-affinity and normally found extrasynaptically (Magnin et al., 2019). $\mathrm{GABA}_{\mathrm{A}}$ receptors containing $\alpha 5$ subunits are very sensitive to low concentrations of anesthetics (Caraiscos et al., 2004), and are upregulated by inflammation and anesthetic exposure, which is a possible mechanism for persistent cognitive impairment (Wang et al., 2012; Zurek et al., 2014). If $\alpha 5$ subunit-containing receptors at the $\mathrm{SST}^{+} / \mathrm{VIP}^{+}$synapse are also upregulated, downstream $\mathrm{SST}^{+} /$excitatory synapses would be inhibited by anesthetic potentiation of $\alpha 5$-containing $\mathrm{GABA}_{\mathrm{A}}$ receptors.

NMDA-type glutamate receptors are inhibited by volatile and dissociative anesthetics with varying potencies. Interneuron subtypes vary in their $\mathrm{N}$-methyl-D-aspartate (NMDA) receptor subunit expression, which alters the kinetic properties of $\mathrm{Ca}^{2+}$ influx (Akgul and McBain, 2016). NMDA receptor signaling is important for $\mathrm{PV}^{+}$interneuron function, and inhibition is associated with a variety of network changes including altered EEG gamma rhythm. NMDA receptor signaling in interneurons, especially the $\mathrm{PV}^{+}$subtype, appears to be critical to ketamine's rapid antidepressant effects. Subanesthetic doses are hypothesized to antagonize $\mathrm{PV}^{+}$interneuron NMDA receptors selectively while sparing those at the pyramidal-pyramidal neuron synapse, thus reducing $\mathrm{PV}^{+}$interneuron activity and disinhibiting pyramidal neurons (Homayoun and Moghaddam, 2007). This selective action at glutamatergic synapses has been attributed to the fast-firing phenotype of $\mathrm{PV}^{+}$interneurons leading to a more depolarized resting membrane potential and greater relief of basal $\mathrm{Mg}^{2+}$ pore block, facilitating NMDA receptor-mediated excitation (Cohen et al., 2015). However, evidence suggests that other interneurons including the $\mathrm{SST}^{+}$subtype may also participate in the antidepressant actions of ketamine (see below). NMDA receptor subunits also control interneuron development in a subtype-specific manner, so distinct anesthetic sensitivities could result in different consequences from exposure during the critical period of neurodevelopment (De Marco Garcia et al., 2015).

\section{ACUTE INTERNEURON SUBTYPE-SPECIFIC ANESTHETIC EFFECTS}

Inhibitory interneurons exert subtype-specific control of excitatory neuron firing patterns at the microcircuit level, and at a microcircuit network level reflected in oscillatory rhythms. Subtle disturbances in cellular function have a cascading impact on network function, as distinct effects on interneuron excitability distort normal action potential output, and alter their contributions to macroscopic rhythms. These large-scale alterations of the excitation/inhibition balance may be a basis for altered neural function observed in association with anesthetic exposure (see below). Given the complexity of neuronal circuits and the delicate balance between excitation 
and inhibition, transmitter-specific effects can produce opposite neurophysiologic results. For example, enhanced inhibitory input onto inhibitory interneurons can lead to disinhibition, or indirect excitation by removal of an inhibitory input (Karnani et al., 2014). Despite these important functional implications, interneuron subtype-selective anesthetic actions have been poorly characterized. The following sections highlight representative examples of known acute anesthetic effects and their implications.

Fast-firing/parvalbumin interneurons Specific anesthetic effects on both intrinsic and synaptic properties have been observed in interneurons with a fast-firing phenotype consistent with $\mathrm{PV}^{+}$interneurons. In the insular cortex, fast-spiking interneurons are less sensitive to propofol depression of membrane excitability compared to other interneurons (regular and late-firing), and especially compared to pyramidal neurons (Kaneko et al., 2016). This is due to differential changes in tonic inhibition and its potentiation by propofol. Fast-spiking interneuron synapses onto pyramidal neurons also show greater facilitation by propofol compared to those from non-fast-spiking interneurons (Koyanagi et al., 2014). Together these observations suggest distinct anesthetic actions of fast-firing interneurons and axo-somatic inhibition of pyramidal neurons. However, at subanesthetic concentrations of isoflurane hippocampal fast-spiking interneuron firing rate is decreased concomitant with an increase in pyramidal neuron firing rate. This suggests that distinct drug effects on a given cell type can emerge at different stages of anesthesia (Zhao et al., 2021).

$\mathrm{SST}^{+}$neuron activity in vivo is very sensitive to isoflurane and urethane (Urban-Ciecko and Barth, 2016). Cortical $\mathrm{SST}^{+}$interneuron visual field tuning is markedly more sensitive to anesthetics compared to pyramidal neurons and $\mathrm{PV}^{+}$interneurons, with profound anesthetic depression of visual stimulus-evoked spiking specific to $\mathrm{SST}^{+}$but not $\mathrm{PV}^{+}$interneurons (Adesnik et al., 2012). SST ${ }^{+}$interneuron excitability is also sensitive to ketamine. Recordings in vivo show that ketamine depression of $\mathrm{SST}^{+}$interneuron activity allows pyramidal neuron disinhibition, with even subanesthetic doses enabling increased pyramidal neuron dendritic $\mathrm{Ca}^{2+}$ influx (Ali et al., 2020). SST ${ }^{+}$interneurons overlap with regular-firing insular interneurons that show greater sensitivity to propofol inhibition of intrinsic excitability compared to fast-firing interneurons (Kaneko et al., 2016).

In vivo recording of $\mathrm{PV}^{+}$and $\mathrm{SST}^{+}$interneurons during upand down-state transitions during urethane anesthesia show different activity profiles in terms of both frequency and phase relation to slow local field potential changes (Zucca et al., 2017). More than just reflecting different responses to anesthesia, these neurons may have different functional roles in cortical state transitions. Optogenetic manipulation of $\mathrm{PV}^{+}$interneuron activity has a greater effect on state transitions, and both endogenous and induced $\mathrm{PV}^{+}$firing is associated with delayed transition from down- to up-state.

The role of SST ${ }^{+}$interneurons in endogenous sleep circuits raises the possibility that they also operate in overlapping anesthesia/sleep circuits (Funk et al., 2017; Moody et al., 2021). In the basal forebrain, select $\mathrm{SST}^{+}$interneuron activation potentiates propofol and isoflurane hypnosis, with a comparably smaller contribution from $\mathrm{PV}^{+}$interneurons (Cai et al., 2021).

Irregular-spiking interneurons at the border of hippocampal stratum lacunosum-moleculare and stratum radiatum exhibit diverse pharmacological properties in rat (Nishikawa and MacIver, 2000). In neurons expressing $\mathrm{I}_{\mathrm{h}}$ (HCN-mediated) currents, $\sim 60 \%$ show $\mathrm{I}_{\mathrm{h}}$ potentiation by halothane with no effect in the rest. In most interneurons, halothane decreases spontaneous firing rate, but for $\sim 8 \%$ of interneurons, halothane depolarizes the resting membrane potential and increases spontaneous firing. Halothane, isoflurane, and sevoflurane all increase spontaneous inhibitory postsynaptic current frequency, consistent with increased presynaptic release probability at unidentified local interneuron-interneuron connections (Nishikawa and MacIver, 2001).

VIP $^{+}$interneuron activity disinhibits excitatory neurons via inhibition of $\mathrm{PV}^{+}$and $\mathrm{SST}^{+}$interneurons, which can be observed with isoflurane anesthesia. In the visual cortex, $\mathrm{VIP}^{+}$ interneuron responses to visual stimuli are similar in awake or anesthetized animals, in contrast to $\mathrm{SST}^{+}$interneurons which show a dramatically different response to the same stimulus depending on the awake or anesthetized state (Jackson et al., 2016). This response profile suggests that, unlike SST ${ }^{+}$ interneurons, $\mathrm{VIP}^{+}$interneurons and their network actions are resistant to anesthesia, although further investigations are needed to delineate whether this apparent anesthetic insensitivity reflects intrinsic cellular pharmacology. As in awake animals, selective optogenetic activation or chemogenetic inhibition of $\mathrm{VIP}^{+}$interneurons can increase or suppress local network activity, respectively under anesthesia (Karnani et al., 2016). VIP ${ }^{+}$ interneuron activity correlates with spontaneous changes in local network activity with isoflurane anesthesia and is an interesting candidate for the circuit basis of fluctuations in activity during stable anesthesia such as burst suppression.

A recent study analyzed interneuron-specific intracellular $\mathrm{Ca}^{2+}$ changes observed immediately after the loss of consciousness (Guo et al., 2021). VIP ${ }^{+}$interneurons showed the highest activity compared to $\mathrm{PV}^{+}$and $\mathrm{SST}^{+}$interneurons, even higher than prior to isoflurane exposure. Whether this simply reflects $\mathrm{VIP}^{+}$interneuron disinhibition due to global activity changes or a more active role in generating hypnosis remains to be tested functionally.

\section{EVIDENCE THAT ANESTHETICS PROMOTE INTERNEURON DYSFUNCTION}

Isoflurane, ketamine, and urethane anesthesia all elicit short-term changes in evoked inhibitory responses, suggesting plasticity of inhibitory synapses, as normal interneuronexcitatory neuron connections are altered during anesthesia (Taub et al., 2013). There is also evidence for long-term changes that persistently alter cognitive function (Vutskits and Xie, 2016). Figure 3 highlights examples of interneuron plasticity or altered function associated with exposure to anesthetics.

Volatile anesthetics have been implicated in persistent neurocognitive dysfunction following emergence from anesthesia (Evered et al., 2018), especially in aged and sick 
individuals, with several preclinical animal models under active study (Eckenhoff et al., 2020). Interneuron cellular and synaptic dysfunction are implicated in neurocognitive dysfunction, including age-related cognitive decline (Rozycka and LiguzLecznar, 2017), raising the possibility that these mechanisms are involved. Upregulated GABAergic signaling via a5 subunitcontaining receptors (Orser and Wang, 2019) implies changes in excitatory/inhibitory balance, consistent with the clinical phenotypes of hypoactivity and impaired working memory. Hippocampal neuroligin 1-Erb4 signaling, which is mostly localized to $\mathrm{PV}^{+}$interneurons and mediates synaptogenesis and synaptic plasticity, is disrupted in aged mice following isoflurane exposure, and its rescue ameliorates the working memory impairment observed days after anesthesia (Li et al., 2014). Another study in aged mice suggests that $\mathrm{PV}^{+}$interneuron death from oxidative stress precipitates cognitive impairment following laparoscopy with isoflurane anesthesia, a phenomenon that probably involves surgery-associated neuroinflammation (Qiu et al., 2016).

\section{ANTIDEPRESSANT EFFECTS OF ANESTHETICS, AND A POTENTIAL ROLE OF INTERNEURON PLASTICITY}

The intravenous anesthetic ketamine has gained attention for eliciting rapid, persistent antidepressant effects from single subanesthetic doses in clinical studies (Berman et al., 2000). $\mathrm{PV}^{+}$and $\mathrm{SST}^{+}$interneurons in the prefrontal cortex have been identified as critical mechanistic initiators. Ketamine inhibition of GluN2B-NMDA receptor signaling in these interneurons is essential for its antidepressant-like effects in rodents (Gerhard et al., 2020). Inhibition of these interneurons and resulting disinhibition of pyramidal neurons results in a surge of glutamate and activation of plasticity mechanisms including increased BDNF release, TrkB, mTOR, and GSK3 $\beta$ signaling, and synaptic protein upregulation (Luscher et al., 2020). Both inhibitory and excitatory synaptic plasticity have been observed in animal models, as reviewed elsewhere(Luscher et al., 2020). For example, neuregulin 1-Erb4 signaling downregulation in $\mathrm{PV}^{+}$interneurons contributes to the antidepressant effects of ketamine (Wang et al., 2014). In support of the idea that ketamine disrupts neuregulin 1-ErB signaling in $\mathrm{PV}^{+}$interneurons to induce inhibitory synaptic plasticity, subanesthetic ketamine can reactivate adult visual plasticity in an ocular dominance model via $\mathrm{PV}^{+}$interneuron neuroligin 1 downregulation and loss of excitatory input (Grieco et al., 2020).

Although less well understood, some clinical data suggest that isoflurane anesthesia can also elicit antidepressant effects and BDNF-mediated neural plasticity in interneuron function. Brief deep isoflurane anesthesia has antidepressant effects comparable to electroconvulsive therapy in human studies (Langer et al., 1985; Engelhardt et al., 1993; Weeks et al., 2013), although inconsistent findings have been reported (Greenberg et al., 1987; Garcia-Toro et al., 2001). Burst suppression has been proposed to replicate the effects of electroconvulsive therapy. In support of an antidepressant effect of isoflurane, research with rodent models found a reversal of depression biomarkers after isoflurane anesthesia with EEG-confirmed burst suppression (Brown et al., 2018). A study investigating antidepressant effects of burst-suppressing isoflurane anesthesia in a rodent model found that some elements of the ketamine antidepressant molecular pathway were replicated, including prefrontal TrkB and GSK3 $\beta$ activation (Antila et al., 2017). There was evidence for interneuron plasticity after anesthesia with a TrkB-dependent increase in $\mathrm{PV}^{+}$interneuron activity, and robust immediateearly gene FosB staining in $\mathrm{PV}^{+}$but not $\mathrm{SST}^{+}$interneurons (Antila et al., 2017). Given that this increased $\mathrm{PV}^{+}$interneuron excitability deviates from the ketamine model of pyramidal cell disinhibition, it will be interesting to see how these molecular events ultimately compare and correlate with antidepressant effects between specific anesthetics.

\section{DEVELOPMENTAL PLASTICITY}

There is also mounting evidence that anesthetics impact developmental plasticity in a cell-type specific manner, raising the possibility that interneuron dysfunction contributes to the long-term cognitive effects of neonatal or prenatal anesthesia. Studies characterizing interneuron development using pan-GABAergic labels show impaired interneuron morphology and function following ketamine exposure (Vutskits et al., 2006, 2007; Aligny et al., 2014). Subtype-specific genetic labeling and functional analysis reveal interesting complexities. Adult interneuron density is sensitive to midazolam anesthesia in a cell-type and developmental-stage specific manner, probably because interneurons undergo subtype differentiation asynchronously (Osterop et al., 2015). A recent study showed that neonatal propofol exposure differentially altered adult interneuron activity during motor learning, with $\mathrm{SST}^{+}$and $\mathrm{PV}^{+}$interneurons being hypoactive and $\mathrm{VIP}^{+}$interneurons being hyperactive compared to vehicle-treated mice, suggesting abnormal synaptic integration and circuit formation (Zhou et al., 2021). Adult $\mathrm{PV}^{+}$interneurons in ketamine treated mice show abnormal synaptic response properties due to altered NMDA receptor subunit expression, specifically an increase in sEPSC frequency and upregulation in NR2B/GluN2B subunits expression (Jeevakumar and Kroener, 2016).

\section{THE PATH FORWARD: UNANSWERED QUESTIONS AND APPROACHES}

Cortical neuron subtype-specific roles have been identified in slow oscillation up- and down-state transitions during sleep and isoflurane (Zucca et al., 2017), and ketamine (Kuki et al., 2015) anesthesia. Are these effects causal in generating loss of consciousness or amnesia? The possibility of circuitspecific anesthetic effects also raises questions for experimental neuroscience since anesthesia is routinely used during in vivo electrophysiological recordings that form the basis for most of what is known about in vivo neurophysiology. The possibility that anesthesia could mask or distort cellular properties is well known, for example, isoflurane and pentobarbital produce profound differences in auditory cortical neuron response 
properties (Cheung et al., 2001). Are there also neuron subtype-specific anesthetic actions or sensitivities that affect neurophysiology in anesthetized animals and thereby complicate data interpretation? How do interneuron subtype-specific sensitivities to anesthetics contribute to network dynamics, oscillatory behavior, and the intraoperative EEG?

Interneuron research has been revolutionized by the use of transgenic mouse models to identify or manipulate genetically defined neurons (Taniguchi et al., 2011; Daigle et al., 2018). Genetic labeling by fluorescent protein biosensor expression is widely used for neuron subtype identification in targeted recordings or anatomical studies. In vivo strategies have been especially powerful to delineate subtype-specific circuit and network function. Optogenetic and chemogenetic methods have been useful in isolating subcortical nuclei critical for hypnosis and arousal and could be applied to interrogate specific neocortical and hippocampal interneuron subtype roles.

As an alternative to genetic labels, interneurons can also be identified by AP waveform and spike timing in relation to known subtype-specific activity during theta and sharp-wave ripples (Kuang et al., 2010). This approach was used to identify diverse interneuron firing patterns under ketamine anesthesia, ranging from no change to induction of rhythmic activity not observed during slow-wave sleep or awake states.

Transcriptomics has illuminated how different programs of gene expression drive phenotypic specialization. A recent meta-analysis suggests that genes related to synaptic transmission are the greatest source of variation associated with neuronal subtype (Paul et al., 2017; Huang and Paul, 2019). Data also suggest that synapses show subtype specialization of presynaptic protein expression (Contreras et al., 2019).

Ex vivo brain slices provide an excellent system in which to investigate anesthetic action on interneuron subtype-specific circuit effects because they allow targeted intracellular recordings and pharmacological accessibility while largely maintaining synaptic connectivity, even generating intrinsic oscillatory rhythms similar to those observed in anesthetized patients (Voss et al., 2019). Brain slices can be maintained for weeks in organotypic culture to investigate long-term changes associated with anesthetic exposure models (Drexler et al., 2010), which provide a valuable model for analyzing long-term anesthetic effects on synaptic plasticity.

This method has enabled site-specific pharmacologic investigations of synaptic modulation (Joksovic et al., 2015; Rodgers et al., 2015), as well as optogenetic (Murphy et al., 2020) and chemogenetic (Jiang-Xie et al., 2019) studies of anesthetic action, all of which hold promise to help delineate cell-type specific and circuit-level pharmacology. However, this system has its own limitations and technical variations that must be considered when comparing data (Humpel, 2015).

\section{NEUROPLASTICITY}

Although general anesthetics are clinically invaluable for their reversible short-term effects on consciousness, evidence is accumulating that they also have the potential to induce neuronal plasticity and long-term changes in cognitive function
(Vutskits, 2012; Platholi and Hemmings, 2021). These outcomes appear steeply dependent not just on drug regime but also on human and animal model properties, e.g., clinical condition, age, surgical treatment, etc. Further investigations into the roles of interneuron subtypes in long-term adverse effects of anesthetics will have to account for immune-mediated changes in interneuron function, for example, $\mathrm{PV}^{+}$interneuron activity increases with neuroinflammation (Feng et al., 2021).

Most mechanistic studies to date specifically investigating interneurons have focused on the $\mathrm{PV}^{+}$subtype. Since different interneurons undergo distinct forms of plasticity, further studies will have to account for interneuron heterogeneity. Given the functional and pharmacological diversity of interneuron responses to acute anesthetic exposure, it will be important to determine whether long-lasting anesthetic effects are also cell-type specific.

\section{GENERALIZABILITY}

In this review, we focused on interneurons of the cortex and hippocampus, but an important question for anesthetic mechanisms is how much of this pharmacology extends to interneurons in other regions that contribute to anesthesia, such as the thalamus, basal forebrain, brainstem, spinal cord, etc? It is far too early to say, especially as investigations into interneuron diversity and characterization of anesthetic-sensitive molecular target expression in these regions are still ongoing. Although the fundamental architecture of these regions is wholly different making a comparison difficult if not impossible, a few striking similarities (such as the presence of interneurons expressing $\mathrm{PV}^{+}$in all these regions) do beg the question of whether any of these associations are recapitulated elsewhere in the brain. For example, there are $\mathrm{PV}^{+}$interneurons in the thalamus, although these are not from the same interneuron progenitor pool as cortical and hippocampal PV+ interneurons (Jager et al., 2021). Basal forebrain interneuron diversity appears similar to cortex and hippocampus, with $\mathrm{PV}^{+}, \mathrm{SST}^{+}$, and nNOS $^{+}$interneurons. Basal forebrain $\mathrm{PV}^{+}$interneurons are also a large subset with fast-firing with narrow AP waveforms, although intrinsic membrane properties including HCN current expression appear to differ from cortical and hippocampal $\mathrm{PV}^{+}$ interneurons (McKenna et al., 2013; Yang et al., 2017). For now, we cautiously suggest circuit roles need to be investigated in a region-specific manner, but that the genetic strategies used to identify interneuron subtype-specific function and pharmacology in the cortex and hippocampus can also be used in other regions. Given that cortical and hippocampal interneurons show great homology and share a common embryological origin of interneuron progenitors, it is possible that other regions with common interneuron precursors may also share adult functional and pharmacological properties relevant to anesthesia.

\section{SUMMARY}

Studies of interneuron cellular and circuit function are rapidly advancing neuroscience research. Recent technical advances have revealed important principles for how inhibitory and excitatory 
neuron ensembles collectively shape neuronal circuit activity and information transfer. However, much of the known anesthetic pharmacology at specific molecular targets has yet to be tested at the interneuronal cellular, microcircuit, or network levels, and predicted interactions will need to be experimentally tested to evaluate their ultimate contributions to the anesthetic behavioral endpoints Application of this knowledge and associated technical advances to the investigation of anesthetic mechanisms will contribute to the elucidation of many long-standing questions regarding the complex actions of general anesthetics on CNS circuit function while also illuminating interneuron subtypespecific neurophysiological function.

\section{REFERENCES}

Adesnik, H., Bruns, W., Taniguchi, H., Huang, Z. J., and Scanziani, M. (2012). A neural circuit for spatial summation in visual cortex. Nature 490, 226-231. doi: $10.1038 /$ nature 11526

Akgul, G., and McBain, C. J. (2016). Diverse roles for ionotropic glutamate receptors on inhibitory interneurons in developing and adult brain. J. Physiol. 594, 5471-5490. doi: 10.1113/JP271764

Ali, F., Gerhard, D. M., Sweasy, K., Pothula, S., Pittenger, C., Duman, R. S., et al. (2020). Ketamine disinhibits dendrites and enhances calcium signals in prefrontal dendritic spines. Nat. Commun. 11:72. doi: 10.1038/s41467-01913809-8

Aligny, C., Roux, C., Dourmap, N., Ramdani, Y., Do-Rego, J. C., Jegou, S., et al. (2014). Ketamine alters cortical integration of GABAergic interneurons and induces long-term sex-dependent impairments in transgenic Gad67-GFP mice. Cell Death Dis. 5:e1311. doi: 10.1038/cddis.2014.275

Antila, H., Ryazantseva, M., Popova, D., Sipila, P., Guirado, R., Kohtala, S., et al. (2017). Isoflurane produces antidepressant effects and induces TrkB signaling in rodents. Sci. Rep. 7:7811. doi: 10.1038/s41598-017-08166-9

Armstrong, C., Krook-Magnuson, E., and Soltesz, I. (2012). Neurogliaform and ivy cells: a major family of nNOS expressing GABAergic neurons. Front. Neural Circuits 6:23. doi: 10.3389/fncir.2012.00023

Barber, A. F., Liang, Q., Amaral, C., Treptow, W., and Covarrubias, M. (2011). Molecular mapping of general anesthetic sites in a voltage-gated ion channel. Biophys. J. 101, 1613-1622. doi: 10.1016/j.bpj.2011.08.026

Berman, R. M., Cappiello, A., Anand, A., Oren, D. A., Heninger, G. R., Charney, D. S., et al. (2000). Antidepressant effects of ketamine in depressed patients. Biol. Psychiatry 47, 351-354. doi: 10.1016/s0006-3223(99) 00230-9

Bhattacharji, A., Klett, N., Go, R. C., and Covarrubias, M. (2010). Inhalational anaesthetics and n-alcohols share a site of action in the neuronal Shaw2 Kv channel. Br. J. Pharmacol. 159, 1475-1485. doi: 10.1111/j.1476-5381.2010. 00642.x

Bonin, R. P., and Orser, B. A. (2008). GABA(A) receptor subtypes underlying general anesthesia. Pharmacol. Biochem. Behav. 90, 105-112. doi: 10.1016/j. pbb.2007.12.011

Brown, P. L., Zanos, P., Wang, L., Elmer, G. I., Gould, T. D., and Shepard, P. D. (2018). Isoflurane but not halothane prevents and reverses helpless behavior: a role for EEG burst suppression?. Int. J. Neuropsychopharmacol. 21, 777-785. doi: 10.1093/ijnp/pyy029

Bryson, A., Hatch, R. J., Zandt, B. J., Rossert, C., Berkovic, S. F., Reid, C. A., et al. (2020). GABA-mediated tonic inhibition differentially modulates gain in functional subtypes of cortical interneurons. Proc. Natl. Acad. Sci. U S A 117, 3192-3202. doi: 10.1073/pnas.1906369117

Buzsaki, G., and Chrobak, J. J. (1995). Temporal structure in spatially organized neuronal ensembles: a role for interneuronal networks. Curr. Opin. Neurobiol. 5, 504-510. doi: 10.1016/0959-4388(95)80012-3

Cai, S., Tang, A. C., Luo, T. Y., Yang, S. C., Yang, H., Liu, C. X., et al. (2021). Effect of basal forebrain somatostatin and parvalbumin neurons in propofol and isoflurane anesthesia. CNS Neurosci. Ther. 27, 792-804. doi: 10.1111/cns. 13635

\section{AUTHOR CONTRIBUTIONS}

IS and $\mathrm{HH}$ both participated in the concept and design of the review, writing, editing, and final approval of the manuscript. All authors contributed to the article and approved the submitted version.

\section{FUNDING}

This work was supported by U.S. National Institutes of Health Grant R01 GM-058055 to HH.

Caraiscos, V. B., Elliott, E. M., You-Ten, K. E., Cheng, V. Y., Belelli, D., Newell, J. G., et al. (2004). Tonic inhibition in mouse hippocampal CA1 pyramidal neurons is mediated by alpha5 subunit-containing gammaaminobutyric acid type A receptors. Proc. Natl. Acad. Sci. US A 101, 3662-3667. doi: 10.1073/pnas.0307231101

Cardin, J. A., Carlen, M., Meletis, K., Knoblich, U., Zhang, F., Deisseroth, K., et al. (2009). Driving fast-spiking cells induces gamma rhythm and controls sensory responses. Nature 459, 663-667. doi: 10.1038/nature08002

Casale, A. E., Foust, A. J., Bal, T., and McCormick, D. A. (2015). Cortical interneuron subtypes vary in their axonal action potential properties. J. Neurosci. 35, 15555-15567. doi: 10.1523/JNEUROSCI.1467-13.2015

Cheung, S. W., Nagarajan, S. S., Bedenbaugh, P. H., Schreiner, C. E., Wang, X., and Wong, A. (2001). Auditory cortical neuron response differences under isoflurane versus pentobarbital anesthesia. Hear. Res. 156, 115-127. doi: 10.1016/s0378-5955(01)00272-6

Cohen, S. M., Ma, H., Kuchibhotla, K. V., Watson, B. O., Buzsaki, G. Froemke, R. C., et al. (2016). Excitation-transcription coupling in parvalbuminpositive interneurons employs a novel CaM kinase-dependent pathway distinct from excitatory neurons. Neuron 90, 292-307. doi: 10.1016/j.neuron.2016.03. 001

Cohen, S. M., Tsien, R. W., Goff, D. C., and Halassa, M. M. (2015). The impact of NMDA receptor hypofunction on GABAergic neurons in the pathophysiology of schizophrenia. Schizophr. Res. 167, 98-107. doi: 10.1016/j.schres.2014.12.026

Contreras, A., Hines, D. J., and Hines, R. M. (2019). Molecular specialization of GABAergic synapses on the soma and axon in cortical and hippocampal circuit function and dysfunction. Front. Mol. Neurosci. 12:154. doi: 10.3389/fnmol. 2019.00154

Daigle, T. L., Madisen, L., Hage, T. A., Valley, M. T., Knoblich, U., Larsen, R. S., et al. (2018). A suite of transgenic driver and reporter mouse lines with enhanced brain-cell-type targeting and functionality. Cell 174, 465-480.e22. doi: 10.1016/j.cell.2018.06.035

De Marco Garcia, N. V., Priya, R., Tuncdemir, S. N., Fishell, G., and Karayannis, T. (2015). Sensory inputs control the integration of neurogliaform interneurons into cortical circuits. Nat. Neurosci. 18, 393-401. doi: 10.1038/nn.3946

Dolphin, A. C., and Lee, A. (2020). Presynaptic calcium channels: specialized control of synaptic neurotransmitter release. Nat. Rev. Neurosci. 21, 213-229. doi: 10.1038/s41583-020-0278-2

Drexler, B., Hentschke, H., Antkowiak, B., and Grasshoff, C. (2010). Organotypic cultures as tools for testing neuroactive drugs - link between in-vitro and in-vivo experiments. Curr. Med. Chem. 17, 4538-4550. doi: $10.2174 / 092986710794183042$

Eckenhoff, R. G., Maze, M., Xie, Z., Culley, D. J., Goodlin, S. J., Zuo, Z., et al. (2020). Perioperative neurocognitive disorder: state of the preclinical science. Anesthesiology 132, 55-68. doi: 10.1097/ALN.0000000000002956

Engelhardt, W., Carl, G., and Hartung, E. (1993). Intra-individual open comparison of burst-suppression-isoflurane-anaesthesia versus electroconvulsive therapy in the treatment of severe depression. Eur. J. Anaesthesiol. 10, 113-118.

Engelhardt, T., Lowe, P. R., Galley, H. F., and Webster, N. R. (2006). Inhibition of neuronal nitric oxide synthase reduces isoflurane MAC and motor activity even in nNOS knockout mice. Br. J. Anaesth. 96, 361-366. doi: 10.1093/bja/ael010 
Evered, L., Silbert, B., Knopman, D. S., Scott, D. A., DeKosky, S. T., Rasmussen, L. S., et al. (2018). Recommendations for the nomenclature of cognitive change associated with anaesthesia and surgery-2018. Br. J. Anaesth. 121, 1005-1012. doi: 10.1016/j.bja.2017.11.087

Fanchaouy, M., Cubano, L., Maldonado, H., and Bychkov, R. (2013). PKC independent inhibition of voltage gated calcium channels by volatile anesthetics in freshly isolated vascular myocytes from the aorta. Cell Calcium 54, 257-265. doi: 10.1016/j.ceca.2013.07.001

Feng, X. Y., Hu, H. D., Chen, J., Long, C., Yang, L., and Wang, L. (2021). Acute neuroinflammation increases excitability of prefrontal parvalbumin interneurons and their functional recruitment during novel object recognition. Brain Behav. Immun. 98, 48-58. doi: 10.1016/j.bbi.2021.08.216

Ferando, I., and Mody, I. (2014). Interneuronal GABAA receptors inside and outside of synapses. Curr. Opin. Neurobiol. 26, 57-63. doi: 10.1016/j.conb.2013. 12.001

Ferando, I., and Mody, I. (2015). in vitro gamma oscillations following partial and complete ablation of delta subunit-containing GABAA receptors from parvalbumin interneurons. Neuropharmacology 88, 91-98. doi: 10.1016/j. neuropharm.2014.09.010

Funk, C. M., Peelman, K., Bellesi, M., Marshall, W., Cirelli, C., and Tononi, G. (2017). Role of somatostatin-positive cortical interneurons in the generation of sleep slow waves. J. Neurosci. 37, 9132-9148. doi: 10.1523/JNEUROSCI.130317.2017

Garcia-Toro, M., Segura, C., Gonzalez, A., Perello, J., Valdivia, J., Salazar, R., et al. (2001). Inefficacy of burst-suppression anesthesia in medication-resistant major depression: a controlled trial. J. ECT 17, 284-288. doi: 10.1097/00124509200112000-00009

Gerhard, D. M., Pothula, S., Liu, R. J., Wu, M., Li, X. Y., Girgenti, M. J., et al. (2020). GABA interneurons are the cellular trigger for ketamine's rapid antidepressant actions. J. Clin. Invest. 130, 1336-1349. doi: 10.1172/JCI130808

Greenberg, L. B., Gage, J., Vitkun, S., and Fink, M. (1987). Isoflurane anesthesia therapy: a replacement for ECT in depressive disorders? Convuls. Ther. 3, 269-277.

Grieco, S. F., Qiao, X., Zheng, X., Liu, Y., Chen, L., Zhang, H., et al. (2020). Subanesthetic ketamine reactivates adult cortical plasticity to restore vision from amblyopia. Curr. Biol. 30, 3591-3603.e8. doi: 10.1016/j.cub.2020. 07.008

Guet-McCreight, A., Skinner, F. K., and Topolnik, L. (2020). Common principles in functional organization of VIP/Calretinin cell-driven disinhibitory circuits across cortical areas. Front. Neural Circuits 14:32. doi: 10.3389/fncir.2020. 00032

Guo, J., Ran, M., Gao, Z., Zhang, X., Wang, D., Li, H., et al. (2021). Celltype-specific imaging of neurotransmission reveals a disrupted excitatoryinhibitory cortical network in isoflurane anaesthesia. EBioMedicine 65:103272. doi: 10.1016/j.ebiom.2021.103272

Haas, H. L., and Gahwiler, B. H. (1992). Vasoactive intestinal polypeptide modulates neuronal excitability in hippocampal slices of the rat. Neuroscience 47, 273-277. doi: 10.1016/0306-4522(92)90243-u

Hafner, G., Witte, M., Guy, J., Subhashini, N., Fenno, L. E., Ramakrishnan, C., et al. (2019). Mapping brain-wide afferent inputs of parvalbumin-expressing GABAergic neurons in barrel cortex reveals local and long-range circuit motifs. Cell Rep. 28, 3450-3461.e8. doi: 10.1016/j.celrep.2019. 08.064

Hardingham, N., Dachtler, J., and Fox, K. (2013). The role of nitric oxide in pre-synaptic plasticity and homeostasis. Front. Cell Neurosci. 7:190. doi: $10.3389 /$ fncel.2013.00190

Hashemi, M., Hutt, A., and Sleigh, J. (2014). Anesthetic action on extra-synaptic receptors: effects in neural population models of EEG activity. Front. Syst. Neurosci. 8:232. doi: 10.3389/fnsys.2014.00232

Hefft, S., and Jonas, P. (2005). Asynchronous GABA release generates long-lasting inhibition at a hippocampal interneuron-principal neuron synapse. Nat. Neurosci. 8, 1319-1328. doi: 10.1038/nn1542

Hemmings, H. C., Jr., Riegelhaupt, P. M., Kelz, M. B., Solt, K., Eckenhoff, R. G., Orser, B. A., et al. (2019). Towards a comprehensive understanding of anesthetic mechanisms of action: a decade of discovery. Trends Pharmacol. Sci. 40, 464-481. doi: 10.1016/j.tips.2019.05.001

Homayoun, H., and Moghaddam, B. (2007). NMDA receptor hypofunction produces opposite effects on prefrontal cortex interneurons and pyramidal neurons. J. Neurosci. 27, 11496-11500. doi: 10.1523/JNEUROSCI.221307.2007

Hu, H., Gan, J., and Jonas, P. (2014). Interneurons. Fast-spiking, parvalbumin(+) GABAergic interneurons: from cellular design to microcircuit function. Science 345:1255263. doi: 10.1126/science. 1255263

$\mathrm{Hu}, \mathrm{H}$., and Jonas, P. (2014). A supercritical density of $\mathrm{Na}(+)$ channels ensures fast signaling in GABAergic interneuron axons. Nat. Neurosci. 17, 686-693. doi: $10.1038 / \mathrm{nn} .3678$

Hu, H., Roth, F. C., Vandael, D., and Jonas, P. (2018). Complementary tuning of $\mathrm{Na}(+)$ and $\mathrm{K}(+)$ channel gating underlies fast and energy-efficient action potentials in GABAergic interneuron axons. Neuron 98, 156-165.e6. doi: 10.1016/j.neuron.2018.02.024

Huang, Z. J., and Paul, A. (2019). The diversity of GABAergic neurons and neural communication elements. Nat. Rev. Neurosci. 20, 563-572. doi: 10.1038/s41583-019-0195-4

Humpel, C. (2015). Organotypic brain slice cultures: a review. Neuroscience 305, 86-98. doi: 10.1016/j.neuroscience.2015.07.086

Itri, J., and Colwell, C. S. (2003). Regulation of inhibitory synaptic transmission by vasoactive intestinal peptide (VIP) in the mouse suprachiasmatic nucleus. J. Neurophysiol. 90, 1589-1597. doi: 10.1152/jn.00332.2003

Jackson, J., Ayzenshtat, I., Karnani, M. M., and Yuste, R. (2016). VIP+ interneurons control neocortical activity across brain states. J. Neurophysiol. 115, 3008-3017. doi: 10.1152/jn.01124.2015

Jager, P., Moore, G., Calpin, P., Durmishi, X., Salgarella, I., Menage, L., et al. (2021). Dual midbrain and forebrain origins of thalamic inhibitory interneurons. eLife 10:e59272. doi: 10.7554/eLife.59272

Jeevakumar, V., and Kroener, S. (2016). Ketamine administration during the second postnatal week alters synaptic properties of fast-spiking interneurons in the medial prefrontal cortex of adult mice. Cereb. Cortex 26, 1117-1129. doi: 10.1093/cercor/bhu293

Jiang, M., and Swann, J. W. (2005). A role for L-type calcium channels in the maturation of parvalbumin-containing hippocampal interneurons. Neuroscience 135, 839-850. doi: 10.1016/j.neuroscience.2005. 06.073

Jiang-Xie, L. F., Yin, L., Zhao, S., Prevosto, V., Han, B. X., Dzirasa, K., et al. (2019). A common neuroendocrine substrate for diverse general anesthetics and sleep. Neuron 102, 1053-1065.e4. doi: 10.1016/j.neuron.2019. 03.033

Jinno, S. (2009). Structural organization of long-range GABAergic projection system of the hippocampus. Front. Neuroanat. 3:13. doi: 10.3389/neuro.05.013. 2009

Joksovic, P. M., Lunardi, N., Jevtovic-Todorovic, V., and Todorovic, S. M. (2015). Early exposure to general anesthesia with isoflurane downregulates inhibitory synaptic neurotransmission in the rat thalamus. Mol. Neurobiol. 52, 952-958. doi: 10.1007/s12035-015-9247-6

Kamatchi, G. L., Durieux, M. E., and Lynch C. 3rd. (2001). Differential sensitivity of expressed L-type calcium channels and muscarinic M(1) receptors to volatile anesthetics in Xenopus oocytes. J. Pharmacol. Exp. Ther. 297, 981-990.

Kaneko, K., Koyanagi, Y., Oi, Y., and Kobayashi, M. (2016). Propofol-induced spike firing suppression is more pronounced in pyramidal neurons than in fast-spiking neurons in the rat insular cortex. Neuroscience 339, 548-560. doi: 10.1016/j.neuroscience.2016.10.016

Karnani, M. M., Agetsuma, M., and Yuste, R. (2014). A blanket of inhibition: functional inferences from dense inhibitory connectivity. Curr. Opin. Neurobiol. 26, 96-102. doi: 10.1016/j.conb.2013.12.015

Karnani, M. M., Jackson, J., Ayzenshtat, I., Hamzehei Sichani, A., Manoocheri, K., Kim, S., et al. (2016). Opening holes in the blanket of inhibition: localized lateral disinhibition by VIP interneurons. J. Neurosci. 36, 3471-3480. doi: 10.1523/JNEUROSCI.3646-15.2016

Keeley, S., Fenton, A. A., and Rinzel, J. (2017). Modeling fast and slow gamma oscillations with interneurons of different subtype. J. Neurophysiol. 117, 950-965. doi: 10.1152/jn.00490.2016

Kepecs, A., and Fishell, G. (2014). Interneuron cell types are fit to function. Nature 505, 318-326. doi: 10.1038/nature 12983

Klausberger, T., and Somogyi, P. (2008). Neuronal diversity and temporal dynamics: the unity of hippocampal circuit operations. Science 321, 53-57. doi: $10.1126 /$ science. 1149381 
Klein, A. S., Donoso, J. R., Kempter, R., Schmitz, D., and Beed, P. (2016). Early cortical changes in gamma oscillations in Alzheimer's disease. Front. Syst. Neurosci. 10:83. doi: 10.3389/fnsys.2016.00083

Koyanagi, Y., Oi, Y., Yamamoto, K., Koshikawa, N., and Kobayashi, M. (2014). Fast-spiking cell to pyramidal cell connections are the most sensitive to propofol-induced facilitation of GABAergic currents in rat insular cortex. Anesthesiology 121, 68-78. doi: 10.1097/ALN.0000000000000183

Kuang, H., Lin, L., and Tsien, J. Z. (2010). Temporal dynamics of distinct CA1 cell populations during unconscious state induced by ketamine. PLoS One 5:e15209. doi: 10.1371/journal.pone.0015209

Kuki, T., Fujihara, K., Miwa, H., Tamamaki, N., Yanagawa, Y., and Mushiake, H. (2015). Contribution of parvalbumin and somatostatin-expressing GABAergic neurons to slow oscillations and the balance in beta-gamma oscillations across cortical layers. Front. Neural Circuits 9:6. doi: 10.3389/fncir.2015. 00006

Langer, G., Neumark, J., Koinig, G., Graf, M., and Schonbeck, G. (1985). Rapid psychotherapeutic effects of anesthesia with isoflurane (ES narcotherapy) in treatment-refractory depressed patients. Neuropsychobiology 14, 118-120. doi: $10.1159 / 000118216$

Lee, S., Hjerling-Leffler, J., Zagha, E., Fishell, G., and Rudy, B. (2010). The largest group of superficial neocortical GABAergic interneurons expresses ionotropic serotonin receptors. J. Neurosci. 30, 16796-16808. doi: 10.1523/JNEUROSCI. 1869-10.2010

Lewis, D. A., Curley, A. A., Glausier, J. R., and Volk, D. W. (2012). Cortical parvalbumin interneurons and cognitive dysfunction in schizophrenia. Trends Neurosci. 35, 57-67. doi: 10.1016/j.tins.2011.10.004

Li, X. M., Su, F., Ji, M. H., Zhang, G. F., Qiu, L. L., Jia, M., et al. (2014). Disruption of hippocampal neuregulin 1-ErbB4 signaling contributes to the hippocampus-dependent cognitive impairment induced by isoflurane in aged mice. Anesthesiology 121, 79-88. doi: 10.1097/ALN.0000000000000191

Li, Y., Xu, J., Xu, Y., Zhao, X. Y., Liu, Y., Wang, J., et al. (2018). Regulatory effect of general anesthetics on activity of potassium channels. Neurosci. Bull. 34, 887-900. doi: 10.1007/s12264-018-0239-1

Liguz-Lecznar, M., Urban-Ciecko, J., and Kossut, M. (2016). Somatostatin and somatostatin-containing neurons in shaping neuronal activity and plasticity. Front. Neural Circuits 10:48. doi: 10.3389/fncir.2016.00048

Lim, L., Mi, D., Llorca, A., and Marin, O. (2018). Development and functional diversification of cortical interneurons. Neuron 100, 294-313. doi: 10.1016/j. neuron.2018.10.009

Loeb, A. L., Raj, N. R., and Longnecker, D. E. (1998). Cerebellar nitric oxide is increased during isoflurane anesthesia compared to halothane anesthesia: a microdialysis study in rats. Anesthesiology 89, 723-730. doi: 10.1097/00000542199809000-00024

Luo, X., Guet-McCreight, A., Villette, V., Francavilla, R., Marino, B., Chamberland, S., et al. (2020). Synaptic mechanisms underlying the network state-dependent recruitment of VIP-expressing interneurons in the CA1 hippocampus. Cereb. Cortex 30, 3667-3685. doi: 10.1093/cercor/ bhz334

Luscher, B., Feng, M., and Jefferson, S. J. (2020). Antidepressant mechanisms of ketamine: focus on GABAergic inhibition. Adv. Pharmacol. 89, 43-78. doi: 10.1016/bs.apha.2020.03.002

Magnin, E., Francavilla, R., Amalyan, S., Gervais, E., David, L. S., Luo, X., et al. (2019). Input-specific synaptic location and function of the alpha5 GABAA receptor subunit in the mouse CA1 hippocampal neurons. J. Neurosci. 39, 788-801. doi: 10.1523/JNEUROSCI.0567-18.2018

Mann, E. O., and Mody, I. (2010). Control of hippocampal gamma oscillation frequency by tonic inhibition and excitation of interneurons. Nat. Neurosci. 13, 205-212. doi: 10.1038/nn.2464

McKenna, J. T., Yang, C., Franciosi, S., Winston, S., Abarr, K. K., Rigby, M. S., et al. (2013). Distribution and intrinsic membrane properties of basal forebrain GABAergic and parvalbumin neurons in the mouse. J. Comp. Neurol. 521, 1225-1250. doi: $10.1002 / \mathrm{cne} .23290$

Melzer, S., and Monyer, H. (2020). Diversity and function of corticopetal and corticofugal GABAergic projection neurons. Nat. Rev. Neurosci. 21, 499-515. doi: 10.1038/s41583-020-0344-9

Moody, O. A., Zhang, E. R., Vincent, K. F., Kato, R., Melonakos, E. D., Nehs, C. J., et al. (2021). The neural circuits underlying general anesthesia and sleep. Anesth. Analg. 132, 1254-1264. doi: 10.1213/ANE.0000000000005361
Murphy, C. A., Raz, A., Grady, S. M., and Banks, M. I. (2020). Optogenetic activation of afferent pathways in brain slices and modulation of responses by volatile anesthetics. J. Vis. Exp. doi: 10.3791/61333

Murthy, S., Niquille, M., Hurni, N., Limoni, G., Frazer, S., Chameau, P., et al. (2014). Serotonin receptor $3 \mathrm{~A}$ controls interneuron migration into the neocortex. Nat. Commun. 5:5524. doi: 10.1038/ncomms6524

Nagasaka, Y., Wepler, M., Thoonen, R., Sips, P. Y., Allen, K., Graw, J. A., et al. (2017). Sensitivity to sevoflurane anesthesia is decreased in mice with a congenital deletion of guanylyl cyclase-1 alpha. BMC Anesthesiol. 17:76. doi: 10.1186/s12871-017-0368-5

Nishikawa, K., and MacIver, M. B. (2000). Membrane and synaptic actions of halothane on rat hippocampal pyramidal neurons and inhibitory interneurons. J. Neurosci. 20, 5915-5923. doi: 10.1523/JNEUROSCI.20-16-05915. 2000

Nishikawa, K., and MacIver, M. B. (2001). Agent-selective effects of volatile anesthetics on GABAA receptor-mediated synaptic inhibition in hippocampal interneurons. Anesthesiology 94, 340-347. doi: 10.1097/00000542-20010200000025

Obermayer, J., Luchicchi, A., Heistek, T. S., de Kloet, S. F., Terra, H., Bruinsma, B., et al. (2019). Prefrontal cortical ChAT-VIP interneurons provide local excitation by cholinergic synaptic transmission and control attention. Nat. Commun. 10:5280. doi: 10.1038/s41467-019-13244-9

Olah, S., Fule, M., Komlosi, G., Varga, C., Baldi, R., Barzo, P., et al. (2009). Regulation of cortical microcircuits by unitary GABA-mediated volume transmission. Nature 461, 1278-1281. doi: 10.1038/nature08503

Orestes, P., and Todorovic, S. M. (2010). Are neuronal voltage-gated calcium channels valid cellular targets for general anesthetics? Channels (Austin) 4, 518-522. doi: 10.4161/chan.4.6.12873

Orser, B. A., and Wang, D. S. (2019). GABAA receptor theory of perioperative neurocognitive disorders. Anesthesiology 130, 618-619. doi: 10.1097/ALN. 0000000000002562

Osterop, S. F., Virtanen, M. A., Loepke, J. R., Joseph, B., Loepke, A. W., and Vutskits, L. (2015). Developmental stage-dependent impact of midazolam on calbindin, calretinin and parvalbumin expression in the immature rat medial prefrontal cortex during the brain growth spurt. Int. J. Dev. Neurosci. 45, 19-28. doi: 10.1016/j.ijdevneu.2015.04.002

Ou, M., Zhao, W., Liu, J., Liang, P., Huang, H., Yu, H., et al. (2020). The general anesthetic isoflurane bilaterally modulates neuronal excitability. iScience 23:100760. doi: 10.1016/j.isci.2019.100760

Overstreet-Wadiche, L., and McBain, C. J. (2015). Neurogliaform cells in cortical circuits. Nat. Rev. Neurosci. 16, 458-468. doi: 10.1038/nrn3969

Palop, J. J., and Mucke, L. (2016). Network abnormalities and interneuron dysfunction in Alzheimer disease. Nat. Rev. Neurosci. 17, 777-792. doi: 10.1038/nrn.2016.141

Pang, D. S., Robledo, C. J., Carr, D. R., Gent, T. C., Vyssotski, A. L., Caley, A., et al. (2009). An unexpected role for TASK-3 potassium channels in network oscillations with implications for sleep mechanisms and anesthetic action. Proc. Natl. Acad. Sci. U S A 106, 17546-17551. doi: 10.1073/pnas.09072 28106

Paul, A., Crow, M., Raudales, R., He, M., Gillis, J., and Huang, Z. J. (2017). Transcriptional architecture of synaptic communication delineates GABAergic neuron identity. Cell 171, 522-539.e20. doi: 10.1016/j.cell.2017. 08.032

Pelkey, K. A., Chittajallu, R., Craig, M. T., Tricoire, L., Wester, J. C., and McBain, C. J. (2017). Hippocampal GABAergic inhibitory interneurons. Physiol. Rev. 97, 1619-1747. doi: 10.1152/physrev.00007.2017

Petilla Interneuron Nomenclature Group, Ascoli, G. A., Alonso-Nanclares, L., Anderson, S. A., Barrionuevo, G., Benavides-Piccione, R., et al. (2008). Petilla terminology: nomenclature of features of GABAergic interneurons of the cerebral cortex. Nat. Rev. Neurosci. 9, 557-568. doi: 10.1038/ nrn2402

Pirker, S., Schwarzer, C., Wieselthaler, A., Sieghart, W., and Sperk, G. (2000). GABA(A) receptors: immunocytochemical distribution of 13 subunits in the adult rat brain. Neuroscience 101, 815-850. doi: 10.1016/s0306-4522(00) 00442-5

Platholi, J., and Hemmings, H. C., Jr. (2021). Effects of general anesthetics on synaptic transmission and plasticity. Curr. Neuropharmacol. doi: 10.2174/1570159X19666210803105232. [Online ahead of print]. 
Posluszny, A. (2019). Updating the picture of layer $2 / 3$ VIP-expressing interneuron function in the mouse cerebral cortex. Acta Neurobiol. Exp. (Wars) 79, 328-337. doi: 10.21307/ane-2019-031

Qiu, L. L., Luo, D., Zhang, H., Shi, Y. S., Li, Y. J., Wu, D., et al. (2016). Nox2-mediated phenotype loss of hippocampal parvalbumin interneurons might contribute to postoperative cognitive decline in aging mice. Front. Aging Neurosci. 8:234. doi: 10.3389/fnagi.2016.00234

Rampil, I. J., Laster, M. J., and Eger 2nd, E. I. (2001). Antagonism of the 5$\mathrm{HT}(3)$ receptor does not alter isoflurane MAC in rats. Anesthesiology 95, 562-564. doi: 10.1097/00000542-200108000-00047

Rengasamy, A., Pajewski, T. N., and Johns, R. A. (1997). Inhalational anesthetic effects on rat cerebellar nitric oxide and cyclic guanosine monophosphate production. Anesthesiology 86, 689-698. doi: 10.1097/00000542-19970300000022

Riegelhaupt, P. M., Tibbs, G. R., and Goldstein, P. A. (2018). HCN and K2P channels in anesthetic mechanisms research. Methods Enzymol. 602, 391-416. doi: 10.1016/bs.mie.2018.01.015

Rodgers, F. C., Zarnowska, E. D., Laha, K. T., Engin, E., Zeller, A., Keist, R., et al. (2015). Etomidate impairs long-term potentiation in vitro by targeting alpha5subunit containing GABAA receptors on nonpyramidal cells. J. Neurosci. 35, 9707-9716. doi: 10.1523/JNEUROSCI.0315-15.2015

Roth, F. C., and Hu, H. (2020). An axon-specific expression of HCN channels catalyzes fast action potential signaling in GABAergic interneurons. Nat. Commun. 11:2248. doi: 10.1038/s41467-020-15791-y

Rozycka, A., and Liguz-Lecznar, M. (2017). The space where aging acts: focus on the GABAergic synapse. Aging Cell 16, 634-643. doi: 10.1111/acel.12605

Rudy, B., and McBain, C. J. (2001). Kv3 channels: voltage-gated K+ channels designed for high-frequency repetitive firing. Trends Neurosci. 24, 517-526. doi: 10.1016/s0166-2236(00)01892-0

Sheffield, M. E., Edgerton, G. B., Heuermann, R. J., Deemyad, T., Mensh, B. D., and Spruston, N. (2013). Mechanisms of retroaxonal barrage firing in hippocampal interneurons. J. Physiol. 591, 4793-4805. doi: 10.1113/jphysiol.2013.258418

Sirois, J. E., Lei, Q., Talley, E. M., Lynch 3rd, C., and Bayliss, D. A. (2000). The TASK-1 two-pore domain $\mathrm{K}+$ channel is a molecular substrate for neuronal effects of inhalation anesthetics. J. Neurosci. 20, 6347-6354. doi: 10.1523/JNEUROSCI.20-17-06347.2000

Sjakste, N., Baumane, L., Meirena, D., Lauberte, L., Dzintare, M., and Kalvins, I. (1999). Drastic increase in nitric oxide content in rat brain under halothane anesthesia revealed by EPR method. Biochem. Pharmacol. 58, 1955-1959. doi: 10.1016/s0006-2952(99)00281-6

Skinner, F. K. (2012). Cellular-based modeling of oscillatory dynamics in brain networks. Curr. Opin. Neurobiol. 22, 660-669. doi: 10.1016/j.conb.2012.02.001

Sohal, V. S., Zhang, F., Yizhar, O., and Deisseroth, K. (2009). Parvalbumin neurons and gamma rhythms enhance cortical circuit performance. Nature 459, 698-702. doi: 10.1038/nature07991

Solt, K., Stevens, R. J., Davies, P. A., and Raines, D. E. (2005). General anestheticinduced channel gating enhancement of 5-hydroxytryptamine type 3 receptors depends on receptor subunit composition. J. Pharmacol. Exp. Ther. 315, 771-776. doi: 10.1124/jpet.105.090621

Sperk, G., Schwarzer, C., Tsunashima, K., Fuchs, K., and Sieghart, W. (1997). GABA(A) receptor subunits in the rat hippocampus I: immunocytochemical distribution of 13 subunits. Neuroscience 80, 987-1000. doi: 10.1016/s03064522(97)00146-2

Steinberg, E. A., Wafford, K. A., Brickley, S. G., Franks, N. P., and Wisden, W. (2015). The role of K(2)p channels in anaesthesia and sleep. Pflugers. Arch. 467, 907-916. doi: 10.1007/s00424-014-1654-4

Stevens, R., Rusch, D., Solt, K., Raines, D. E., and Davies, P. A. (2005). Modulation of human 5-hydroxytryptamine type $3 \mathrm{AB}$ receptors by volatile anesthetics and n-alcohols. J. Pharmacol. Exp. Ther. 314, 338-345. doi: 10.1124/jpet.105. 085076

Tallent, M. K., and Qiu, C. (2008). Somatostatin: an endogenous antiepileptic. Mol. Cell Endocrinol. 286, 96-103. doi: 10.1016/j.mce.2007.12.004

Taniguchi, H., He, M., Wu, P., Kim, S., Paik, R., Sugino, K., et al. (2011). A resource of Cre driver lines for genetic targeting of GABAergic neurons in cerebral cortex. Neuron 71, 995-1013. doi: 10.1016/j.neuron.2011.07.026

Taub, A. H., Katz, Y., and Lampl, I. (2013). Cortical balance of excitation and inhibition is regulated by the rate of synaptic activity. J. Neurosci. 33, 14359-14368. doi: 10.1523/JNEUROSCI.1748-13.2013
Taverna, S., Tkatch, T., Metz, A. E., and Martina, M. (2005). Differential expression of TASK channels between horizontal interneurons and pyramidal cells of rat hippocampus. J. Neurosci. 25, 9162-9170. doi: 10.1523/JNEUROSCI.2454-05. 2005

Turi, G. F., Li, W. K., Chavlis, S., Pandi, I., O’Hare, J., Priestley, J. B., et al. (2019). Vasoactive intestinal polypeptide-expressing interneurons in the hippocampus support goal-oriented spatial learning. Neuron 101, 1150-1165.e8. doi: 10.1016/j.neuron.2019.01.009

Udakis, M., Pedrosa, V., Chamberlain, S. E. L., Clopath, C., and Mellor, J. R. (2020). Interneuron-specific plasticity at parvalbumin and somatostatin inhibitory synapses onto CA1 pyramidal neurons shapes hippocampal output. Nat. Commun. 11:4395. doi: 10.1038/s41467-020-18074-8

Urban-Ciecko, J., and Barth, A. L. (2016). Somatostatin-expressing neurons in cortical networks. Nat. Rev. Neurosci. 17, 401-409. doi: 10.1038/nrn. 2016.53

Vardya, I., Drasbek, K. R., Dosa, Z., and Jensen, K. (2008). Cell type-specific GABA A receptor-mediated tonic inhibition in mouse neocortex. J. Neurophysiol. 100, 526-532. doi: 10.1152/jn.01224.2007

Verret, L., Mann, E. O., Hang, G. B., Barth, A. M., Cobos, I., Ho, K., et al. (2012). Inhibitory interneuron deficit links altered network activity and cognitive dysfunction in Alzheimer model. Cell 149, 708-721. doi: 10.1016/j.cell.2012.02. 046

Vinet, J., and Sik, A. (2006). Expression pattern of voltage-dependent calcium channel subunits in hippocampal inhibitory neurons in mice. Neuroscience 143, 189-212. doi: 10.1016/j.neuroscience.2006.07.019

Vitalis, T., Cases, O., Passemard, S., Callebert, J., and Parnavelas, J. G. (2007). Embryonic depletion of serotonin affects cortical development. Eur. J. Neurosci. 26, 331-344. doi: 10.1111/j.1460-9568.2007.05661.x

Voss, L. J., Garcia, P. S., Hentschke, H., and Banks, M. I. (2019). Understanding the effects of general anesthetics on cortical network activity using ex vivo preparations. Anesthesiology 130, 1049-1063. doi: 10.1097/ALN. 0000000000002554

Vutskits, L. (2012). General anesthesia: a gateway to modulate synapse formation and neural plasticity?. Anesth. Analg. 115, 1174-1182. doi: 10.1213/ANE. 0b013e31826a1178

Vutskits, L., and Xie, Z. (2016). Lasting impact of general anaesthesia on the brain: mechanisms and relevance. Nat. Rev. Neurosci. 17, 705-717. doi: 10.1038/nrn. 2016.128

Vutskits, L., Gascon, E., Potter, G., Tassonyi, E., and Kiss, J. Z. (2007). Low concentrations of ketamine initiate dendritic atrophy of differentiated GABAergic neurons in culture. Toxicology 234, 216-226. doi: 10.1016/j.tox. 2007.03.004

Vutskits, L., Gascon, E., Tassonyi, E., and Kiss, J. Z. (2006). Effect of ketamine on dendritic arbor development and survival of immature GABAergic neurons in vitro. Toxicol. Sci. 91, 540-549. doi: 10.1093/toxsci/kfj180

Wang, N., Zhang, G. F., Liu, X. Y., Sun, H. L., Wang, X. M., Qiu, L. L., et al. (2014). Downregulation of neuregulin 1-ErbB4 signaling in parvalbumin interneurons in the rat brain may contribute to the antidepressant properties of ketamine. J. Mol. Neurosci. 54, 211-218. doi: 10.1007/s12031-014 $-0277-8$

Wang, D. S., Zurek, A. A., Lecker, I., Yu, J., Abramian, A. M., Avramescu, S., et al. (2012). Memory deficits induced by inflammation are regulated by alpha5subunit-containing GABAA receptors. Cell. Rep. 2, 488-496. doi: 10.1016/j. celrep.2012.08.022

Weeks, H. R. 3rd, Tadler, S. C., Smith, K. W., Iacob, E., Saccoman, M., White, A. T., et al. (2013). Antidepressant and neurocognitive effects of isoflurane anesthesia versus electroconvulsive therapy in refractory depression. PLoS One 8:e69809. doi: 10.1371/journal.pone.0069809

Yamamoto, K., and Kobayashi, M. (2018). Opposite roles in short-term plasticity for N-Type and P/Q-type voltage-dependent calcium channels in GABAergic neuronal connections in the rat cerebral cortex. J. Neurosci. 38, 9814-9828. doi: 10.1523/JNEUROSCI.0337-18.2018

Yang, Y., Ou, M., Liu, J., Zhao, W., Zhuoma, L., Liang, Y., et al. (2020). Volatile anesthetics activate a leak sodium conductance in retrotrapezoid nucleus neurons to maintain breathing during anesthesia in mice. Anesthesiology 133, 824-838. doi: 10.1097/ALN.0000000000003493

Yang, C., Thankachan, S., McCarley, R. W., and Brown, R. E. (2017). The menagerie of the basal forebrain: how many (neural) species are there, what 
do they look like, how do they behave and who talks to whom? Curr. Opin. Neurobiol. 44, 159-166. doi: 10.1016/j.conb.2017.05.004

Yavorska, I., and Wehr, M. (2016). Somatostatin-expressing inhibitory interneurons in cortical circuits. Front. Neural Circuits 10:76. doi: $10.3389 /$ fncir. 2016.00076

Ying, S. W., Abbas, S. Y., Harrison, N. L., and Goldstein, P. A. (2006). Propofol block of $\mathrm{I}(\mathrm{h})$ contributes to the suppression of neuronal excitability and rhythmic burst firing in thalamocortical neurons. Eur. J. Neurosci. 23, 465-480. doi: 10.1111/j.1460-9568.2005.04587.x

Zaitsev, A. V., Povysheva, N. V., Lewis, D. A., and Krimer, L. S. (2007). P/Qtype, but not $\mathrm{N}$-type, calcium channels mediate GABA release from fast-spiking interneurons to pyramidal cells in rat prefrontal cortex. J. Neurophysiol. 97, 3567-3573. doi: 10.1152/jn.01293.2006

Zhao, W., Zhang, M., Liu, J., Liang, P., Wang, R., Hemmings, H. C., et al. (2019). Isoflurane modulates hippocampal cornu ammonis pyramidal neuron excitability by inhibition of both transient and persistent sodium currents in mice. Anesthesiology 131, 94-104. doi: 10.1097/ALN.000000000002753

Zhao, W., Zhao, S., Zhu, T., Ou, M., Zhang, D., Sun, H., et al. (2021). Isoflurane suppresses hippocampal high-frequency ripples by differentially modulating pyramidal neurons and interneurons in mice. Anesthesiology 135, 122-135. doi: 10.1097/ALN.0000000000003803

Zhou, C., Johnson, K. W., Herold, K. F., and Hemmings, H. C., Jr. (2019). Differential inhibition of neuronal sodium channel subtypes by the general anesthetic isoflurane. J. Pharmacol. Exp. Ther. 369, 200-211. doi: 10.1124/jpet. 118.254938

Zhou, C., Liang, P., Liu, J., Ke, B., Wang, X., Li, F., et al. (2015). HCN1 channels contribute to the effects of amnesia and hypnosis but not immobility of volatile anesthetics. Anesth. Analg. 121, 661-666. doi: 10.1213/ANE.0000000000000830

Zhou, H., Xie, Z., Brambrink, A. M., and Yang, G. (2021). Behavioural impairments after exposure of neonatal mice to propofol are accompanied by reductions in neuronal activity in cortical circuitry. Br. J. Anaesth. 126, 1141-1156. doi: 10.1016/j.bja.2021.01.017

Zucca, S., D'Urso, G., Pasquale, V., Vecchia, D., Pica, G., Bovetti, S., et al. (2017). An inhibitory gate for state transition in cortex. eLife 6:e26177. doi: 10.7554/eLife.26177

Zurek, A. A., Yu, J., Wang, D. S., Haffey, S. C., Bridgwater, E. M., Penna, A., et al. (2014). Sustained increase in alpha5GABAA receptor function impairs memory after anesthesia. J. Clin. Invest. 124, 5437-5441. doi: 10.1172/JCI76669

Conflict of Interest: $\mathrm{HH}$ is the editor in chief of the British Journal of Anesthesia, is a consultant for Elsevier (Philadelphia, PA, USA), and receives research funding unrelated to this study from Instrumentation Laboratory/Werfen (Bedford, MA, USA).

The remaining author declares that the research was conducted in the absence of any commercial or financial relationships that could be construed as a potential conflict of interest.

Publisher's Note: All claims expressed in this article are solely those of the authors and do not necessarily represent those of their affiliated organizations, or those of the publisher, the editors and the reviewers. Any product that may be evaluated in this article, or claim that may be made by its manufacturer, is not guaranteed or endorsed by the publisher.

Copyright $\odot 2022$ Speigel and Hemmings. This is an open-access article distributed under the terms of the Creative Commons Attribution License (CC BY). The use, distribution or reproduction in other forums is permitted, provided the original author(s) and the copyright owner(s) are credited and that the original publication in this journal is cited, in accordance with accepted academic practice. No use, distribution or reproduction is permitted which does not comply with these terms. 